\title{
Viral-vector delivered anti-angiogenic therapies to the eye
}

\author{
Sanna Koponen 1, Emmi Kokki 1, Kati Kinnunen 2 and Seppo Ylä-Herttuala 3,*
}

1 A.I. Virtanen Institute for Molecular Sciences, University of Eastern Finland, Kuopio, Finland; sanna.k.koponen@uef.fi; Emmi.kokki@uef.fi

2 Department of Ophthalmology, Kuopio University Hospital, Kuopio, Finland; Kati.Kinnunen@kuh.fi

3 Gene Therapy Unit, Kuopio University Hospital, Kuopio, Finland

* Address correspondence to this author at the A.I. Virtanen Institute for Molecular Sciences, University of Eastern Finland, P.O. Box 1627, 70211 Kuopio, Finland; Tel/Fax: +358403552075; E-mail: seppo.ylaherttuala@uef.fi.

\begin{abstract}
Pathological vessel growth harms vision and may finally lead to vision loss. Anti-angiogenic gene therapy with viral vectors for ocular neovascularization has shown great promise in preclinical studies. Most of the studies has conducted with different adeno-associate serotype vectors. In addition, Adeno and lentivirus vectors have been used. Therapy has targeted to block vascular endothelial growth factors or other pro-angiogenic factors. Clinical trials of intraocular gene therapy for neovascularization have shown the treatment to be safe without severe adverse events or systemic effects. Nevertheless, clinical studies have not proceeded phase 2 trials further.
\end{abstract}

Keywords: Gene therapy; ocular neovascularization; viral vectors; preclinical; clinical trials; antiangiogenesis; AAV

\section{Introduction}

Ocular neovascularization is one of the most common causes of moderate and severe vision loss in developed countries. Pathological angiogenesis, which is mainly induced through vascular endothelial growth factors (VEGF) and their receptors, is involved in many of these vision impairing ocular disorders such as age-related macular degeneration (AMD), diabetic retinopathy (DR) and corneal neovascularization [1]. In the healthy eye, VEGF is necessary for the maintenance of retinal pigment epithelium (RPE) and choriocapillaris [2]. Treatment of the eye possess several challenges why the oral or topical administration of the drug does not achieve therapeutic concentration in the eye [3]. As most of the vision impairing diseases affect the retina, repeated anti-VEGF injections into the vitreous are currently the most commonly used treatment method in order to inhibit angiogenesis [4]. The treatment with anti-VEGF injections is effective, but it also has disadvantages due to the need for repeated injections, which places significant burden on the patients and health-care system and poses a risk on adverse events including inflammation, retinal detachment, and subretinal and vitreous hemorrhage.

Gene therapy with viral vectors for ocular diseases has shown great promise for the future. It provides an alternative treatment for re-occurring injections. Viral vectors are efficient in transducing different tissues and provide long-term treatment options [5]. Successful gene therapy relies on the efficient gene delivery to the target cells, which can be achieved by selecting the right delivery system, specific promoter elements and administration route. An eye is an optimal gene therapy target as it can be easily injected by using only small injection volumes of virus still leading to successful expression inside the eye $[6,7]$. In addition, due the blood-retina-barrier, the gene therapy can be targeted with high titers into the eye minimizing systemic biodistribution and side effects. Genome editing has brought new possibilities to edit gene expression in the eye. FDA approved the first gene transfer treatment for ocular disease in 2017, where a subretinal delivery of 
AAV2-mediated voretigene neparvovecrzyl (Luxturna $\left.{ }^{\circledR}\right)$ is done for treating inherited biallelic RPE65 mutation-associated retinal dystrophy [8]. The approval of the gene therapy proves that it is a usable tool for treating ocular diseases.

\section{Angiogenesis}

Angiogenesis is the growth of blood vessels and is essential for organ growth in the embryo and in the placenta during pregnancy, in the cycling ovary and in wound healing in adults [9]. Angiogenesis is tightly controlled and balanced between proangiogenic and antiangiogenic factors. One of the most important proangiogenic factor is the VEGF, which induce endothelial cell proliferation, migration and new vessel formation. The VEGF signals are mediated through tyrosine kinase receptors VEGFR-1, -2 and -3 and coreceptors neuropilins 1 and 2 [10]. VEGF-A is one of the strongest vascular permeability inducers which expression is increased in hypoxic conditions. Soluble VEGF-receptors sVEGFR-1, -2 and -3 function as competitive inhibitors of the binding of VEGFs to the membrane bound receptors and therefore regulating VEGF signaling [11]. There are also other molecules that affect angiogenesis like angiopoietin-2 (ANG-2), fibroblast growth factors (FGF) and chemokines, released by hypoxic, inflammatory or tumor cells [12].

In normal healthy eye, VEGF is expressed in retina, choroid-RPE, iris and conjunctiva [2]. In retina VEGF, expression is localized in the ganglion, inner nuclear- and RPE cell layers. VEGF is crucial for cellular homeostasis as a neurotrophic and cell survival factor but it is also one of the critical mediators of pathological neovascularization [13]. Intraocular VEGF is upregulated by hypoxia or inflammation (Figure 1). Upregulated VEGF drives neovascularization and increases vascular permeability. This leads to different complications such as leaky vessels, retinal detachment, fibrovascular proliferation, retinal exudation, edema and ultimately photoreceptor neuron death and blindness. Pathological angiogenesis in the eye includes many diseases for example of AMD, DR, retinopathy of prematurity (ROP) and corneal neovascularization [1].
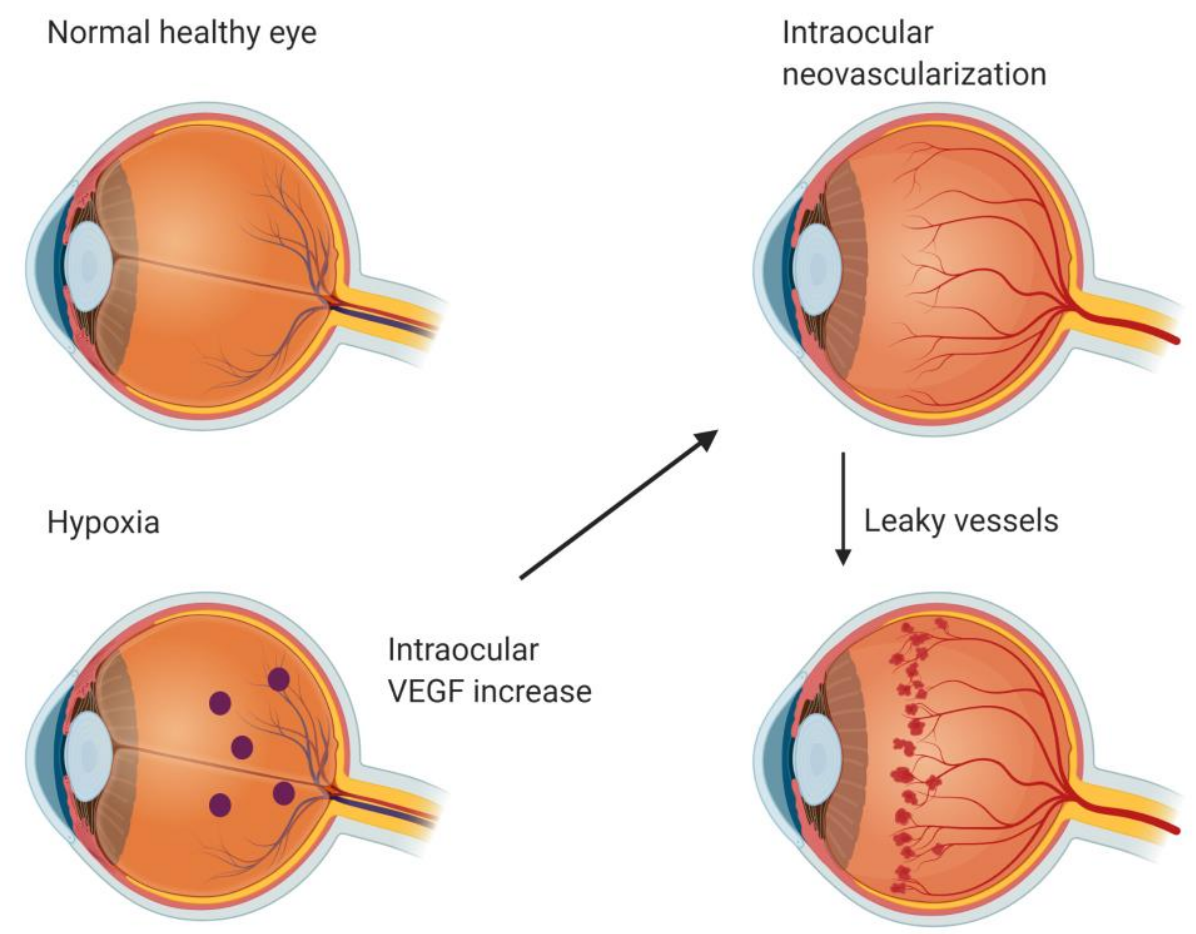

Figure 1. Intraocular neovascularization. Hypoxia upregulates VEGF expression which leads to intraocular neovascularization and at the end leaky vessels. Created with BioRender.com 
Currently available treatment options for ocular neovascularization, especially for wet AMD, include photodynamic therapy (PDT), laser therapy and anti-VEGF therapies [14]. The use of laser therapy and photodynamic therapy for treatment has been declined since. Laser surgery and PDT have a limited visual improvement potential and in addition, laser surgery even has a risk of producing vision loss. Three most commonly used anti-VEGF therapies are aflibercept, ranibizumab and bevacizumab, which bind to VEGF and prevent their signal transduction through VEGFR [4]. These VEGF inhibitors are injected intravitreally into the eye. Aflibercept is a recombinant fusion protein of human VEGFR-1 and VEGFR-2 binding domains fused with the Fc domain of human IgG1 [15]. Ranibizumab is a recombinant antibody fragment of the humanized anti-VEGF monoclonal antibody. Bevacizumab is a full-length recombinant humanized anti-VEGF monoclonal antibody (IgG). Food and Drug Administration (FDA) has approved aflibercept and ranibizumab for the treatment of AMD. Bevacizumab has not been approved by FDA or EMA [16] for ophthalmic use, but its safety and efficacy have shown in multiple clinical AMD and DR trials. Anti-VEGF therapies have been effective to treat ocular neovascularization [4]. However, intravitreal injections are required monthly, which places a significant burden on the patients and the health-care system. Injections also pose a risk of serious ocular adverse events, including endophthalmitis, retinal detachment, and subretinal and vitreous hemorrhage

\section{Gene therapy and viral vectors}

Gene therapy involves transfer of nucleic acids into a cell either to correct dysfunctional gene or to provide new cellular functions [17]. Gene therapy can be achieved by the substitution of the altered gene, inhibiting the gene expression or insertion of a new gene [18]. Genes can be transferred by viral or non-viral vectors. Non-viral gene delivery can be achieved by physical or chemical methods. In the physical methods, the permeability of the cell membrane is increased by physical force and in the chemical methods, natural or synthetic carriers are used. Compared with viral vectors, non-viral vectors are less immunogenic, less toxic, and easily produced. On the other hand, they are less effective to express transgenes at therapeutic levels. Viral vectors are more efficient in transducing cells and inducing long-term gene expression than non-viral vectors [19]. Gene expression time is short with non-viral vectors versus viral vectors, where gene-expression can last for weeks, months or even some years. Viral vectors have limitations for example limited transgene capacity or they might cause immune responses. There are many different viral vectors used in gene therapy for example adeno-, adeno associated-, retro-, lenti-, baculo, herpes simplex-, and Epstein-Barr-viruses. Successful gene therapy relies on the efficient gene delivery to target cells and long-term gene-expression [7]. It can be achieved by selecting the right delivery system, specific promoter elements and administration route. As a target for gene therapy, the eye has many advantages: eye anatomy is well known, it is easy to access and examine, it is relatively immune privileged and for study-wise the other eye can be used as a control.

Adenovirus (Adv) is a non-enveloped double-stranded DNA vector, which can transduce dividing and non-dividing cells [7, 20]. Adenovirus can carry large genes and it does not integrate into the host cell genome. There are over 50 different human adenovirus serotypes. Adenoviral vectors transduce different types of cells in the eye [21]. After the intravitreal injection of the adenoviral vector, expressing green fluorescent protein (GFP) transduced corneal endothelial cells, trabecular and iris cells. In subretinally injected eyes, transduction was detected in photoreceptors and RPE cells. In one study adenoviral vector, expressing LacZ was detected in the nerve cell layer and ganglion cell layer of the retina [22]. In another adenovirus serotype 5 was shown to transduce efficiently anterior chamber corneal endothelium, trabecular meshwork, ciliary body, iris and some Müller and INL cells [6]. The highest transduction was observed 7 days after injection. After 1 month of injection, GFP expression was detected mainly in RPE cells. An inflammatory response was observed 3 and 7 days after the injections by increasing number of 
F4/80-immunocreative cells. The time range of how long GFP is expressed also depends on AdV serotype [23]. It was shown that Ad35-GFP vector had prolonged GFP expression compared with Ad5-GFP vector. GFP expression was detected 4 months after the Ad35GFP injection but had diminished by 8 months. Adenoviral gene therapy in clinical trials has shown a mild inflammatory response which have been easily managed [24, 25].

Adeno associated virus (AAV) is a single-stranded DNA vector, which can transduce dividing and non-dividing cells [26]. AAV provides long-term gene expression and can integrate into the host cell genome. AAV has many different serotypes, which transduce different cells in the eye. AAV2 expressing GFP has been shown to transduce RPE, the retinal ganglion cell layer (RGCL) and some cells in the inner nuclear layer (INL) and the outer plexiform layer (OPL) [6]. After 1 month, GFP expression was also detected in the optic nerve, inner plexiform layer, ciliary body, trabecular meshwork, and iris. After 3 and 6 months of injection, expression was detected in RGCL and INL. In one study, subretinal injection of AAV5 and AAV2 was shown to transduce photoreceptor and RPE cells in the murine retina [27]. AAV5 transduced more photoreceptor cells than AAV2. In the time course for expression was faster with AAV5 than with AAV2. Only minimal to moderate ocular inflammatory responses have been detected after AAV injections into the eye in animal models [28, 29] and in clinical trials [28, 30-33].

Lentiviruses (LV) and retroviruses are single-stranded RNA vectors [34]. Lentiviruses can transduce dividing and non-dividing cells but retroviruses only dividing cells. Both virus vectors can integrate stably into the host cell genome. Most commonly used retro- and lentiviral vectors for gene therapy are the human immunodeficiency virus type 1 (HIV-1) and murine Moloney leukemia virus (MLV) [35]. The use of retroviruses for gene therapy has been reduced [7] after one study outcome where four patients developed $\mathrm{T}$ cell leukemia 31-68 months after the gamma retroviral gene delivery [36]. As a consequence of the vector integration proto-oncogenes were activated in all four patients. Lentivirus vectors transduce different cells in the eye. It was shown that lentivirus vector expressing GFP transduce RPE, corneal endothelium, trabecular meshwork, ciliary body, iris pigmented epithelium, anterior chamber, INL and ocular muscles after intravitreal injection [6]. It was shown that subretinal injection of lentiviral vector expressing GFP transduced RPE [37], choroid and sclera layers [38]. Inflammatory responses in the eyes with lentiviral vector injections have shown to be very moderate or not significant $[39,40]$. In one study subretinal lentiviral vector show strong retinal and ocular inflammatory reaction, which resolved over the follow-up period [41]. In clinical study it was shown that subretinal injection of the lentiviral vector was well tolerated with no dose-limiting toxicities and there was little or no ocular inflammation [42].

Baculoviruses (BV) are double-stranded DNA vectors, which are capable of transferring genes into various mammalian cells without viral replication [43]. Baculoviruses have high transgene capacity and have low cytotoxicity. It has been shown that baculovirus transduces different cells in the eye. Subretinal injection of baculovirus encoding GFP under the CMV-promoter (rBV-CMV-GFP) led GFP expression in RPE cells, which peaked 1-4 days after injection but was not detected after 2 months [44]. When rBV-CMV-GFP was injected intravitreally GFP expression was detected in the corneal endothelium, the retinal inner nuclear layer, the ganglion cell layer and the RPE cell layer. After 2 days of subretinal injection, the infiltration of macrophages was observed in the subretinal space and across the retina and after intravitreal injection in the anterior chamber and vitreous. After 3 days also CD11b+ and CD4+ cells were found, but after 8 days inflammation was almost completely resolved. In other study intravitreally injected BV-GFP led GFP expression in the photoreceptor cells and RPE after 6 days of injection [22]. In this study inflammatory responses were also detected in this study in the anterior segment, retina and in the optic nerve head of the eye.

\section{Pre-clinical antiangiogenic studies}

\subsection{VEGF-blocking agents}


In preclinical in vivo studies, the most commonly used viral vector has been AAV during the last three years. Some studies have been conducted with adeno- and lentivirus vectors (Table 1). One way to inhibit VEGF is to use VEGF-blocking antibodies. In one study, choroidal neovascularization (CNV) was prevented by the inducible over-expression of Eylea (aflibercept) with a single-injection of the AAV vector. Eylea inducibility was achieved by using riboswitches [45]. Riboswithes are gene control elements found in archea, bacteria and eukaryote [46]. These gene control elements regulate gene expression by directly binding to a specific ligand. Most riboswitches are cis-acting gene control elements resides usually in the $5^{\prime}$-untranslated region (UTR) that consists of aptamer domain (ligand sensing structure) and an expression platform, which together undergoes conformational alterations upon ligand binding. A secretable Eylea transgene cassette was delivered usind AAV capsid mutant vector with improved retinal penetrance [45]. TC45 riboswitch was incorporated in the 3 '-UTR of the expression cassette and modulation of intraocular concentration of Eylea was possible through the oral dosing of tetracycling (activating ligand). Regular C57BL/6J mice were intravitreally injected with these constructs. After seven weeks of injections and 7 days of CNV induction by laser it was shown that constitutive expression of Eylea prevented CNV formation significantly.

A codon-optimised cDNA of the aflibercept protein is encoded in AAV2.7m8 capsid, ADVM-022 [47]. It was shown that in non-human primates (African green monkeys) intravitreal injection of ADVM-022 suppressed exudative lesions and subretinal fibro-vascular complexes in CNV 2 and 4 weeks after the laser-induction. The injection was made 13 months before laser induction and there were no clinical signs indicative of ADVM-022 related systemic effects observed.

A VEGF-blocking antibody, single-chain fragment variable ( $\mathrm{scFv}$ ) antibody, which lacks the Fc domain was expressed via AAV2/8 with a strong CAG promoter and a WPRE (woodchuck hepatitis virus post-transcriptional regulatory element) sequence to enhance expression [48]. AAV-anti-VEGF scFv was shown to reduce CNV in the laser-induced CNV mouse model.

RGX-314 is AAV8 vector containing an expression cassette for a humanized antibody fragment that binds human VEGF (anti-VEGFfab) [49, 50]. It was shown that subretinal injection of RGX-314 suppressed neovascular area in transgenic mice expressing human VEGF in the retina. In a rat model of hVEGF, suprachoroidal injection of RGX-314 between sclera and choroid suppressed VEGF induced vascular leakage and vasodilation [49].

Pathological angiogenesis can be inhibited via soluble VEGF receptors [51]. In one study intravitreally injected AAV2 expressing a soluble variant of VEGF receptor 1 decreased CNV lesion size 14 days after laser induction in the laser induced CNV mouse model. Additionally, the infiltrated number of inflammatory and apoptotic cells were decreased.

\subsection{Other pro-angiogenic factors}

Many other pro-angiogenic and anti-angiogenic factors have also been studied to inhibit angiogenesis. A mammalian target of rapamycin (mTOR) is a serine-threonine protein kinase [52]. The mTOR signaling pathway consists of two complexes mTOR complex 1 and 2. mTOR1 is sensitive to rapamycin and responsible for cell growth, proliferation, angiogenesis, protein and lipid synthesis and autophagy regulation. Recombinant AAV derived from self-complementary AAV2, expressing a short hairpin RNA blocks the activity of mTOR complexes 1 and -2. Intravitreal injection of AAV-mTOR shRNA was shown to suppress angiogenesis and inflammation in laser induced CNV mouse model [52] and reduce neovascularization in rat oxygen-induced retinopathy (OIR) model [53]. In other study optimal viral genome size for efficient AAV assembly was ensured by using a stuffer DNA derived from 3' UTR of the human UBE3A gene [54]. It was shown that this vector reduced CNV in the laser-induced mouse model. 
Endostatin is an endogenous antiangiogenic protein that down regulates HIF-1 $\alpha$ [55]. Endostatin has been reported to reduce CNV [56]. In one study AAV2 vector comprising a RPE-specific promotor and HRE was used to regulate human endostatin production [57] and after ubretinal injection of it reduced CNV areas $80 \%$ in a mouse model of laser-induced CNV after 21 days of injection. Endostatin mRNA levels were increased significantly at 3, 7 and 14 days after the laser and returned to baseline levels after 45 days.

Calreticulin anti-angiogenic domain (CAD) comprising amino acids 1-180 is a potent endogenous inhibitor of angiogenesis and has anti-inflammatory properties [58]. Intravitreal injection of AAV2 expressing CAD significantly suppressed retinal neovascularization in oxygen-induced retinopathy rat model [59]. Subretinal injection of this vector also reduced CNV lesions in laser-induced mouse model after 21 days of subretinal injection and 14 days after laser induction.

Hepatocyte growth factor (HGF) is a mitogen that promotes epithelial and endothelial cell motility, cell migration, branching- and/or tubular morphogenesis and may induce VEGF production in different cells [60]. Kringle1 domain of HGF was shown to exhibit both antiangiogenic and antitumor cell effects [61]. Intravitreal injection of AAV expressing Kringle1 domain of HGF inhibited pathological retinal neovascularization in oxygen-induced retinopathy (OIR) mouse model compared with vehicle [62]. Treated group showed good vascular distribution and the non-perfusion area was limited to the optic papilla indicating that the overexpression of this fragment may be a potent treatment for ocular neovascularization.

Galectins are carbohydrate-binding proteins that are essential for tumor angiogenesis [63]. Galectin-1 (GAL-1) is linked to cell adhesion, migration, survival and signaling and is associated with inflammatory disorders, cancer [63] and with proliferative diabetic retinopathy [64]. Adenoviral Gal-1-RNAinterference was used to silence Gal-1 [65]. Intravitreal injection of d-Gal-1-RNAi decreased significantly retinal neovascularization and retinal hypoxia in the OIR mouse model.

\subsection{Pre-clinical studies with genome editing}

Genome editing has become possible in living organisms [66]. In a single event, it is possible to add desirable or to remove undesirable alleles. Highly efficient way to edit genome is the clustered regularly interspaced short palindromic repeats (CRISPR)/Cas9 (CRISPR associated protein) system. This system targets DNA sequences via nucleotide base pairing and RNA-guided endonuclease. There are different types of CRISPR/Cas systems. The AAV1 mediated CRISPR/Cas9 driven by an endothelial cell-specific promoter pICAM2 was used to deplete VEGFR2 in vascular endothelial cells [67]. It was shown that AAV-CRISRP/Cas9 suppressed neovascularization in the mouse models of OIR and laserinduced CNV. Type V CRISPR/Cas system contains a large protein called Cpf1 [68]. Cpf1 differs from Cas9 in several ways. Cpf1 (Lachnospiraceae bacterium ND2006) was targeted to VEGF and HIF1 $\alpha$ [69]. Intravitreally injected AAV9-Cpf1-Vegfa or -Hif1a reduced the area of CNV of laser-induced CNV mouse model 1 week after laser induction and 6 weeks after injection. AAV-Cpf1-Vegfa or -Hif1a also reduced VEGF protein levels in RPE. There were no off-target effects in the retina or RPE cells.

\subsection{Pre-clinical studies with multigenic viral vectors}

The application of a multigenic viral vector producing multiple microRNAs has been used in anti-angiogenic studies. Multigenic means that vector can hold multiple gene cassettes for co-expression of several therapeutic factors. A combined expression of microRNAs targeting VEGF-A mRNA and fluorescent reporters was enabled by a lentiviral vector carrying back-to-back RNApolII-driven expression cassettes [37]. Expression of miRNAs was targeted to RPE cells by including a vitelliform macular dystrophy 2 VMD2 promotor. It was shown that subretinal injection of lentiviral anti-VEGF miRNAs reduced 
choroidal neovascularization in the laser induced CNV mouse model 21 days after injection. Lentiviral-eGFP expression was shown to be stable and widespread 6 days, 21 days and even 9 months after injection.

Multigenic AAV vectors expressing anti-VEGF miRNA and a secreted antiangiogenic protein pigment endothelial-derived factor (PEDF) driven by the RPE-specific promoter provides improved protection against CNV [70]. It was shown that 57 days after subretinal injection of AAV5 vector either expressing antiangiogenic miRNAs or co-expression of antiangiogenic miRNAs and PEDF significantly decreased CNV area in a laser induced CNV mouse model. PEDF is a member of serine protease inhibitor family and acts as a multifunctional protein in different physiological and pathophysiological mechanisms such as angiogenesis, inflammatory responses, and neuroprotection [71]. PEDF functions as a major antiangiogenic factor in the retina and vitreous body.

\subsection{Pre-clinical studies of corneal neovascularization}

Not many studies to treat corneal neovascularization have been conducted. In one study it was shown that intrastromal injection of AAV vector containing codon optimized human leucocyte antigen G1+ G5 (scAAV8G9- optHLA-G1 + G5) prevented corneal neovascularization and decreased the immune cell infiltration into the cornea over 2 months after the chemical corneal burn in rabbits [72]. However, one strong and two very mild scAAV8G9 capsid-specific neutralizing antibody responses were detected. HLA-G has immune-inhibitory functions and it is well known to protect fetus from destruction by mother's immune system [73]. It also acts as an immune escape mechanism for tumors. HLA-G binds immune cells and inhibits their function. HLA-G protein was detected in adult human corneas which means that it may contribute to the maintenance of the privileged immune status of cornea [74].

\subsection{Pre-clinical studies of retinopathy of prematurity}

VEGF inhibition is an attractive treatment for ROP, but it might delay or halt normal retinal vascularization and it is shown to have systemic implications like lowering VEGF serum levels [75]. This raises the concerns of the effects on developing organ systems, including lungs and brain. Thus, other methods inhibiting neovascularization have to be considered. In one study, endothelial-cell-specific knockdown of VEGFR 2 or downstream STAT3 was shown to inhibit VEGF-induced retinopathy without delaying physiologic retinal vascular development [76]. Lentivirus vector under the VE-cadherin promoter was used to deliver shRNAs to knockdown VEGFR2 or STAT3. The subretinal injection of these vectors, reduced significantly intravitreal neovascularization in the rat OIR model that represents human ROP.

In another study shRNA to VEGF was developed to inhibit the overexpression of VEGF-A in Müller cells [77]. It was shown that knockdown of a VEGF by a subretinal injection of lentivirus carrying shRNA driven by a cell specific promoter significantly reduced intravitreal neovascular area in the rat OIR model. Thinning of the photoreceptor and ONL layers were also detected suggesting that knockdown of VEGF in Müller cells may have harmful effects on photoreceptors.

Table 1. Pre-clinical animal studies with viral vector mediated gene therapy for ocular neovascularization.

\begin{tabular}{llllll}
\hline Animal model & Vector & Injection & Anti-angiogenic factor & Indication & $\begin{array}{c}\text { Referenc } \\
\text { site }\end{array}$ \\
\hline Laser induced & rAAV2/2- & intravitreal & aflibercept & wet ADM & [45] \\
CNV in mouse & riboswitch & & & \\
\hline
\end{tabular}




\begin{tabular}{|c|c|c|c|c|c|}
\hline $\begin{array}{l}\text { Laser induced } \\
\text { CNV in non-hu- } \\
\text { man primate }\end{array}$ & AAV2.7m8 & intravitreal & $\begin{array}{l}\text { codon-optimised cDNA of the } \\
\text { aflibercept protein (ADVM- } \\
022 \text { ) }\end{array}$ & wet ADM & [47] \\
\hline $\begin{array}{l}\text { Laser induced } \\
\mathrm{CNV} \text { in mouse }\end{array}$ & AAV2/8 & subretinal & $\begin{array}{l}\text { anti-VEGF single-chain frag- } \\
\text { ment variable (scFv) antibody }\end{array}$ & wet ADM & {$[48]$} \\
\hline $\begin{array}{l}\text { Transgenic mice } \\
\text { expressing hu- } \\
\text { man VEGF in } \\
\text { retina } \\
\text { (rho/VEGF mice) } \\
\text {, rats expressing } \\
\text { human VEGF in } \\
\text { retina }\end{array}$ & AAV8 & $\begin{array}{l}\text { subretinal, } \\
\text { supracho- } \\
\text { roidal }\end{array}$ & $\begin{array}{l}\text { humanized antibody fragment } \\
\text { that binds human VEGF (anti- } \\
\text { VEGFfab) (RGX-314) }\end{array}$ & wet ADM & {$[49,50]$} \\
\hline $\begin{array}{l}\text { Laser induced } \\
\mathrm{CNV} \text { in mouse }\end{array}$ & AAV2 & intravitreal & soluble variant of VEGFR-1 & wet ADM & {$[51]$} \\
\hline $\begin{array}{l}\text { Laser induced } \\
\text { CNV and oxy- } \\
\text { gen-induced } \\
\text { retinopathy in } \\
\text { mouse, }\end{array}$ & $\begin{array}{l}\text { AAV1- } \\
\text { CRISPR/Cas9 }\end{array}$ & intravitreal & $\begin{array}{l}\text { CRISPR/Cas9 targeted to } \\
\text { VEGFR } 2\end{array}$ & $\begin{array}{l}\text { wet ADM, } \\
\text { ROP }\end{array}$ & [67] \\
\hline
\end{tabular}

\begin{tabular}{|c|c|c|c|c|c|}
\hline $\begin{array}{l}\text { Laser induced } \\
\text { CNV in mouse }\end{array}$ & $\begin{array}{l}\text { AAV9-CRISPR- } \\
\text { LbCpf1 }\end{array}$ & intravitreal & $\begin{array}{l}\text { CRISPR-LbCpf1 targeted to } \\
\text { VEGF A and HIF1 } \alpha\end{array}$ & wet ADM & {$[68]$} \\
\hline $\begin{array}{l}\text { Oxygen-in- } \\
\text { duced retinopa- } \\
\text { thy in rat, laser } \\
\text { induced CNV in } \\
\text { mouse }\end{array}$ & AAV2 & intravitreal & mTOR shRNA, & $\begin{array}{l}\text { wet ADM, } \\
\text { ROP, DR }\end{array}$ & {$[52-54]$} \\
\hline $\begin{array}{l}\text { Laser induced } \\
\text { CNV in mouse }\end{array}$ & scAAV2 & subretinal & endostatin & wet ADM & {$[57]$} \\
\hline $\begin{array}{l}\text { Oxygen-in- } \\
\text { duced retinopa- } \\
\text { thy in rat, laser } \\
\text { induced CNV in } \\
\text { mouse }\end{array}$ & scAAV2 & $\begin{array}{l}\text { intravitreal, } \\
\text { subretinal }\end{array}$ & $\begin{array}{l}\text { calreticulin anti-angiogenic do- } \\
\text { main }(\mathrm{CAD})\end{array}$ & wet ADM, DR & {$[59]$} \\
\hline $\begin{array}{l}\text { Oxygen-in- } \\
\text { duced retinopa- } \\
\text { thy in mouse }\end{array}$ & rAAV & intravitreal & $\begin{array}{l}\text { Kringle1 domain of hepatocyte } \\
\text { growth factor (HGFK1) }\end{array}$ & wet ADM, DR & {$[62]$} \\
\hline $\begin{array}{l}\text { Oxygen-in- } \\
\text { duced retinopa- } \\
\text { thy in mouse }\end{array}$ & Adenovirus GV120 & intravitreal & Galetin-1-RNAinterference & ROP & {$[65]$} \\
\hline
\end{tabular}




\begin{tabular}{|c|c|c|c|c|c|}
\hline $\begin{array}{l}\text { Corneal chemi- } \\
\text { cal burn in a } \\
\text { rabbit }\end{array}$ & $\begin{array}{l}\text { AAV8/9 chimeric } \\
\text { capsid (8G9) }\end{array}$ & $\begin{array}{l}\text { corneal in- } \\
\text { trastromal }\end{array}$ & $\begin{array}{l}\text { codon optimized human leu- } \\
\text { cocyte antigen G1+ G5 }\end{array}$ & $\begin{array}{l}\text { Corneal neo- } \\
\text { vascularization }\end{array}$ & {$[72]$} \\
\hline $\begin{array}{l}\text { Oxygen-in- } \\
\text { duced retinopa- } \\
\text { thy in rat }\end{array}$ & Lentivirus & subretinal & shRNAs to VEGFR2 or STAT3 & $\mathrm{ROP}$ & {$[76]$} \\
\hline $\begin{array}{l}\text { Oxygen-in- } \\
\text { duced retinopa- } \\
\text { thy in rat }\end{array}$ & Lentivirus & subretinal & $\begin{array}{l}\text { VEGF-A or VEGF-A164 } \\
\text { shRNA }\end{array}$ & ROP & [77] \\
\hline $\begin{array}{l}\text { Laser induced } \\
\text { CNV in mouse }\end{array}$ & Lentivirus & subretinal & microRNAs targeting VEGF-A & wet ADM & [37] \\
\hline $\begin{array}{l}\text { Laser induced } \\
\mathrm{CNV} \text { in mouse }\end{array}$ & AAV5 & subretinal & $\begin{array}{l}\text { PEDF, multiple miRNAs tar- } \\
\text { geting the VEGFA gene }\end{array}$ & wet ADM & {$[70]$} \\
\hline
\end{tabular}

$\mathrm{AAV}=$ adeno associate virus, $\mathrm{ADV}=$ adenovirus, $\mathrm{ADM}=$ age-related macular degeneration $\mathrm{CNV}=$ choroidal neovascularization, $\mathrm{DR}=$ diabetic retinopathy, $\mathrm{LV}=$ lentivirus, $\mathrm{ROP}=$ retinopathy of prematurity

\section{Gene therapy clinical trials of neovascular ocular diseases}

In 2019, there were 37 gene therapy clinical trials for ocular diseases making it $1.2 \%$ of all gene therapy clinical trials [78]. In autumn 2020, there were seven active, recruiting clinical trials for ocular neovascularization utilizing three different gene therapy applications: soluble CD59, cDNA of aflibercept, and soluble anti-VEGF monoclonal antibody fragment related to ranibizumab. Thus, all the studies are based on AAV vectors and rely on a single administration. Most of the studies are in Phase I assessing the efficacy and safety.

\subsection{AAVCAGsCD59}

Unlike the other on-going clinical studies, AAVCAGsCD59 gene therapy trial uses a novel target for treating neovascular ocular diseases. CD59 is a glycoprotein expressed in several cell types, such as endothelial cells [79]. Normal cells produce CD59 that block membrane attack complex (MAC), but the trend towards increased MAC expression [80] and reduced expression of CD59 is evident in both atrophic [81] and neovascular AMD patients [82]. Thus, as the complement cascade is upregulated, the more MAC is formed than the body can protect itself against leading to cell damage and death.

AAVCAGsCD59 gene therapy (NCT03585556) utilizes AAV2 expressing soluble CD59 [83]. Gene therapy is intended to protect retinal cells that are responsible for central vision. The soluble recombinant version of the naturally occurring CD59 inhibits the formation of the MAC and prevents binding of the C9 proteins required to complete the terminal step of the complement-mediated cell lysis. The purpose of the Phase 1 study is to evaluate the number of anti-VEGF antibody injections that are required after a single intravitreal injection of AAVCAGsCD59 in patients with treatment of new onset wet AMD.

AAVCAGsCD59 is administered at a dose of 3.6x1011 vg or 1.1×1012 vg via intravitreal injection seven days after a single intravitreal injection of anti-VEGF. Anti-VEGF will be injected at day 0 to treat the CNV per standard of care and enable the AAVCAGsCD59 adequate time to enter the ganglion cells in the retina and start producing the transgene product. All eyes will then be treated with intravitreal anti-VEGF antibody monthly up to 12 months as needed based on disease activity. A long-term follow-up safety exam will occur at month 24 . 


\subsection{ADVM-022}

Two studies utilize AAV vector for the expression of aflibercept (ADVM-022). The study subjects are assigned to receive one of the two doses (2x1011 vg/eye or 6x1011 vg/eye) of ADVM-022 intravitreally [84, 85].

The Phase 1 study (NCT03748784) will evaluate subjects with active choroidal neovascularization secondary to AMD [84]. The primary endpoint for this study is safety and tolerability of ADVM-022, but key secondary outcome measures include the effect of ADVM-022 on the best corrected visual acuity, the effect of ADVM-022 on anatomic outcomes as measured by spectral-domain OCT (SD-OCT), and the need for rescue aflibercept injections. All subjects will continue to be assessed for 104 weeks following the treatment with ADVM-022. In interim data, beyond 15 months from the gene transfer, no serious adverse events were noted without the need for any rescue injections in the high-dose group [86].

Based on the promising results from the Phase 1 clinical trial of ADVM-022 in patients with wet AMD [87],phase 2 gene therapy trial for diabetic macular edema (DME) (NCT04418427) has been started [85]. Study subjects will be assigned to receive one of the two doses of ADVM-022 or assigned to the control arm to receive a sham ocular injection with a preceding aflibercept injection. Subjects who are assigned to receive ADVM-022 will be further randomized to receive a preceding aflibercept or sham ocular injection. All subjects will be assessed regularly and will receive additional aflibercept injections should DME disease activity progress. The primary objective is to assess the durability of a single intravitreal injection of ADVM-022. All subjects will be followed for 48 weeks after randomization.

\subsection{RGX-314}

The third study drug is RGX-314, an AAV8 vector containing a transgene for a soluble anti-VEGF monoclonal antibody fragment related to ranibizumab [88]. The expressed protein is designed to neutralize VEGF activity, modifying the pathway for the formation of new leaky blood vessels and retinal fluid accumulation.

The first Phase I/IIa dose-escalation study is designed to evaluate the safety and tolerability of RGX-314 gene therapy in subjects with previously treated neovascular AMD (NCT03066258) [88]. Five doses (3.9x109 GC/eye to and 2.5x1011 GC/eye) of subretinal delivery of RGX-314 will be studied. Safety will be the primary focus for the initial 24 weeks after RGX-314 administration. Following the completion of the primary study period, subjects will continue to be assessed until 104 weeks following the treatment with RGX-314.

There is also a long-term follow-up study of RGX-314 (NCT03999801) [89]. This is a prospective, observational study designed to evaluate the long-term safety of RGX-314 for up to 5 years post-RGX-314 administration inclusive of the parent study. Eligible participants are those who were previously enrolled in the clinical study in which they received a single subretinal administration of RGX-314.

The results are not yet published, but based on preliminary data from the sponsor, RGX-314 is well-tolerated across all cohorts, with no drug-related serious adverse events [90]. Sixteen SAEs not related to RGX-314, including two ocular procedure-related SAEs, were reported in ten patients. Positive long-term potential efficacy signals were sustained over 2 years in patients who received 6x1010 GC/eye. In this group, the mean change in visual acuity across all six patients was markedly improved over two years, with a mean BCVA improvement of +14 letters. Patients also demonstrated long-term reductions in anti-VEGF treatment burden and three out of six patients received no anti-VEGF injections over 2 years following one-time administration of RGX-314. Additionally, long-term intraocular RGX-314 protein expression was stable in this group over 2 years. The mean RGX-314 protein expression level was $227.2 \mathrm{ng} / \mathrm{ml}$ at 2 years, compared to $217.8 \mathrm{ng} / \mathrm{ml}$ at 
6 months in the group receiving 6x1010 GC/eye. Consistent with previous results, intraocular RGX-314 protein expression levels increased in a dose-dependent manner across cohorts.

Another phase 2 study utilizes suprachoroidal space as an administration route for RGX-314 gene therapy. A dose-escalation study evaluates the efficacy, safety, and tolerability of RGX-314 gene therapy in subjects with neovascular AMD (NCT04514653) [91] with doses of $2.5 \times 1011$ GC/eye or 5x1011 GC/eye [92]. Suprachoroidal gene therapy with RGX-314 is compared to intravitreal injection of monthly $0.5 \mathrm{mg}$ ranibizumab. Suprachoroidal administration route is also exploited in a phase 2 study for participants with nonproliferative and proliferative DR without center involved-diabetic macular edema (NCT04567550) [93].

The third study drug is RGX-314, an AAV8 vector containing a transgene for a soluble anti-VEGF monoclonal antibody fragment related to ranibizumab [87]. The expressed protein is designed to neutralize VEGF activity, modifying the pathway for the formation of new leaky blood vessels and retinal fluid accumulation.

\section{Completed clinical trials for ocular neovascularization}

Also, the completed viral vector mediated gene therapy trials for ocular neovascular diseases from previous last years have mostly relied on AAV as the gene carrier. The studies applied anti-angiogenic factors or soluble VEGF receptors to find new treatments for AMD.

\section{1. sFLT-1}

Soluble FLT-1 encoded by AAV2 has been utilized in several studies with neovascular AMD patients. sFLT-1 is a soluble human VEGFR-1 acting as a VEGF antagonist [94]. In the first phase 1 study, gene therapy was reported to be safe and well tolerated. All patients received ranibizumab injections at baseline and in week 4 [95]. A week after the first injection, the patients in the gene therapy group received subretinal injection of 100 $\mu \mathrm{L}$ of the AAV2 with a dose $1 \times 10^{10} \mathrm{vg}$ or $1 \times 10^{11} \mathrm{vg}$. Patients in the control group did not receive any gene therapy treatment.

Both treatment groups were well tolerated, and no ocular or systemic adverse events were attributed to the vector [95]. Adverse events related to the study procedures were minor and noted in three of six patients, including subconjunctival or subretinal hemorrhage and mild cell debris in the anterior vitreous. There were no major differences between the treatment groups in terms of CPT, BCVA, and the number of rescue treatments.

Patients received an injection only to one eye. [95] Nevertheless, vector shedding, both for vector DNA and viral capsid proteins, were detected in samples of serum, urine, saliva, and tears from both study and fellow eyes. The rAAV.sFLT-1 vector DNA was detected by quantitative PCR only in tear specimens obtained 1 day after injection from the injected eye of two patients but was undetectable in the next study point in 3 weeks. Serum concentrations of VEGF remained unchanged over the course of the study. The week 52 assessment in the rAAV.sFLT-1-treated patients showed no evidence of vision loss or atrophy in the paramacular area of the bleb site. In the gene therapy group, the median centre point thickness CPT was $549 \mu \mathrm{m}$ at baseline, decreasing to $311 \mu \mathrm{m}$ at week 52. The BCVA in the treatment group improved from a median of 40 EDTRS letters at baseline to 50 EDTRS letters at the same time. Four of six patients in the treatment group required zero rescue injections, and the other two required one rescue injection each.

In another phase 1 clinical trial, a single injection of one of the four dose-ranging cohorts $\left(2 \times 10^{8} \mathrm{vg}\right.$ to $\left.2 \times 10^{10} \mathrm{vg}\right)$ was injected to AMD patients and followed up for 52 weeks [96]. Compared with the first stud, the injection was done intravitreally and there were no control groups. Gene therapy seemed to be safe and well tolerated at all doses. Although the maximum tolerated dose was not detected, the patients receiving the highest dose of viral vector experienced likely study-drug-related adverse effects (pyrexia and intraocular inflammation) and a decrease in BCVA, whereas in patients receiving lower 
doses, the BCVA increased during the study, whereas the mean change from baseline BCVA in patients receiving $2 \times 10^{10} \mathrm{vg}$ showed a slight early improvement followed by a gradual decline, but overall little change. In patients with intraretinal or subretinal fluid at baseline judged to be reversible, of those six showed fluid reduction, whereas five showed no fluid reduction.

No sFLT01 was detectable in aqueous humour in patients receiving lower doses, but five of ten patients who received an injection of $2 \times 10^{10} \mathrm{vg}$ had detectable amounts of sFLT01 that peaked at 26 weeks and slightly decreased afterward [96]. AAV2-sFLT01 vector DNA sequences were not detected in the blood, nasopharynx, urine, or semen of any patients at any time point. Neither there were any systemic adverse events likely to be related to gene therapy.

In Phase 2a study a bigger group $(n=32)$ of AMD patients were treated subretinally with rAAV.sFLT-1 $(1 \times 1011 \mathrm{vg})$ [30]. The study protocol was the same as in phase 1 trial of Rakoczy et. al. [95]. No serious ocular AE was reported in the gene therapy group [30]. The most common ocular AE in the rAAV.sFLT-1 group was intraocular hemorrhage. The majority of cases were deemed to be mild in nature, visually insignificant with no permanent sequelae. Two ocular AEs considered possibly to be related to rAAV.sFLT-1 were eye inflammation, and anterior chamber inflammation, which were mild in nature. No systemic safety signals were observed relative to the treatment.

AAV2 capsid was not detected in samples collected at any time point. In the gene therapy group, rAAV.sFLT-1 DNA was detected transiently in the tears from the treated eye in a subset of patients (13/21), in the tears of the fellow eye in one patient, in the saliva in one patient, and in the urine in one patient. All these occurrences resolved prior to the week 4 visit and none of the patients had detectable vector DNA in their blood.

In the gene therapy group, the median change in BCVA was 1.0 ETDRS letters from baseline to week 52 whereas in the control group, the median change in BCVA from baseline was -5.0 ETDRS letters. Twelve of 21 gene therapy patients experienced maintenance or improvement of vision versus 4 of 11 control patients. The difference in median change in CPT between the gene therapy and control groups was $95.0 \mu \mathrm{m}$. The median number of ranibizumab injections was 2.0 for the gene therapy group compared to 4.0 for the control group.

Follow-up combined Phase 1 and 2 trials up to 3 years [95]. Between 1 and 3 years, no serious adverse events were related to gene therapy. Even though BVCA improved from baseline and remained higher in 1, 2, and 3 years in the patients receiving sFLT-1, the difference was not statistically significant. In addition, the gene therapy did not show superiority in CPT or the number of required VEGF injections compared with the control group.

\subsection{RetinoStat}

Besides AAV vector, also other viral vectors have been used as the carrier. A study with lentiviral equine infectious anemia virus (EIAV) vector expressing anti-angiogenic factors endostatin and angiostatin (RetinoStat) evaluated the safety of the treatment after a single subretinal injection [42]. Doses of $2.4 \times 104,2.4 \times 105$, or $8.0 \times 105$ transduction units (TU) were injected to AMD patients with neovascularization. The study had no control groups.

Each of the doses was well-tolerated with no dose-limiting toxicities [42]. However, there was one procedure-related serious adverse event, a macular hole. RNA sequences were detected in the plasma of one subject on day 0 but not thereafter. There was a vector dose-related increase in aqueous humor levels of endostatin and angiostatin with high reproducibility among subjects within cohorts. Aqueous humor levels remained stable through the last measurement at week 48. In order to assess long-term expression beyond week 48, available samples from subjects with significant levels of expression were measured during the long-term follow-up study. Long-term follow-up demonstrated that endostatin and angiostatin expression was maintained at last measurement (2.5 years in 
eight subjects and over 4 years in two subjects). However, the treatment did not achieve significant beneficial effects in visual acuity nor in anatomical outcomes. Seven subjects from 15 in the highest dose group received anti-VEGF injections due to persistent or increased disease activity. In contrast, only one injection was given to one patient in other groups.

\subsection{PEDF}

Also adenoviral vector has been used for gene delivery in anti-angiogenic ocular clinical trials. This is a study of Ad5-mediated gene therapy encoding cDNA for human pigment epithelium-derived factor (PEDF) [25]. PEDF, originally extracted from cultured human fetal retinal pigment epithelial cells [97], is an antiangiogenic factor. It exists naturally in the human eye, but its levels are decreased in diseases characterized by ocular neovascularization like diabetic retinopathy [98, 99] and AMD [100,101].

In a phase I study, AdPEDF was delivered once via intravitreal injection into one eye with the worst visual acuity 22. The study intended to study the safety of gene therapy in patients with advanced neovascular AMD. Eight dose levels of AdPEDF from 106 to 109.5 particle units (PU) were investigated until 12 months without the presence of a control group. Intravitreous injection of AdPEDF was generally well tolerated at all doses and no drug-related serious adverse events were discovered. Seven patients (25\%) had transient inflammation. Sputum and urine were negative for replicating adenovirus 3 weeks after gene delivery. Anti-adenoviral neutralizing antibody titers did not consistently rise after intravitreous injection of AdPEDF, but several patients showed a small increase, and one patient had a substantial increase at week 3 that returned to baseline at week 12 . Patients treated with the highest dose, 108-109.5 PU, showed stabilization in CNV lesion size and mild improvement in visual acuity (around +2 EDTRS letters) up to one year after injection.

Table 2. On-going and finished clinical trials with viral vector mediated gene therapy for ocular neovascularization.

\begin{tabular}{|c|c|c|c|c|c|}
\hline Clinical trial & Vector & $\begin{array}{l}\text { Injection } \\
\text { site }\end{array}$ & anti-angiogenic factor & Indication & $\begin{array}{l}\text { Referen } \\
\text { ce }\end{array}$ \\
\hline AAVCAGsCD59 (NCT03585556) & AAV2 & intravitreal & soluble CD59 & wet AMD & {$[83]$} \\
\hline ADVM-022 (NCT03748784) & AA7 & intravitreal & $\begin{array}{l}\text { codon-optimised } \\
\text { cDNA of the afliber- } \\
\text { cept protein }\end{array}$ & wet AMD & {$[84]$} \\
\hline ADVM-022 (NCT04418427) & AA7 & intravitreal & $\begin{array}{l}\text { codon-optimised } \\
\text { cDNA of the afliber- } \\
\text { cept protein }\end{array}$ & $\begin{array}{l}\text { diabetic macular } \\
\text { edema }\end{array}$ & {$[85]$} \\
\hline $\begin{array}{l}\text { RXG-314 (NCT03066258, } \\
\text { NCT03999801) }\end{array}$ & AAV8 & subretinal & $\begin{array}{l}\text { soluble anti-VEGF } \\
\text { monoclonal antibody } \\
\text { fragment related to } \\
\text { ranibizumab }\end{array}$ & wet AMD & {$[88,89]$} \\
\hline RXG-314 (NCT04514653) & AAV8 & $\begin{array}{l}\text { subrachoroi } \\
\text { dal }\end{array}$ & $\begin{array}{l}\text { soluble anti-VEGF } \\
\text { monoclonal antibody } \\
\text { fragment related to } \\
\text { ranibizumab }\end{array}$ & wet AMD & [91] \\
\hline RXG-314 (NCT04567550) & AAV8 & $\begin{array}{l}\text { subrachoroi } \\
\text { dal }\end{array}$ & $\begin{array}{l}\text { soluble anti-VEGF } \\
\text { monoclonal antibody }\end{array}$ & $\begin{array}{l}\text { diabetic } \\
\text { retinopathy }\end{array}$ & [93] \\
\hline
\end{tabular}


fragment related to

ranibizumab

\begin{tabular}{|c|c|c|c|c|c|}
\hline Soluble FLT-1 (NCT01494805) & AAV2 & subretinal & Soluble FLT-1 & wet AMD & [95] \\
\hline Soluble FLT-1 (NCT01494805) & AAV2 & subretinal & Soluble FLT-1 & wet AMD & {$[30]$} \\
\hline Soluble FLT-1 (NCT01024998) & AAV2 & intravitreal & Soluble FLT-1 & wet AMD & [96] \\
\hline $\begin{array}{l}\text { RetinoStat (NCT01301443, } \\
\text { NCT01678872) }\end{array}$ & lentivirus & subretinal & $\begin{array}{l}\text { endostatin and angio- } \\
\text { statin }\end{array}$ & wet AMD & [42] \\
\hline AdPEDF (NCT00109499) & $\begin{array}{l}\text { Adenovi- } \\
\text { rus } 5\end{array}$ & intravitreal & $\begin{array}{l}\text { cDNA for human pig- } \\
\text { ment epithelium-de- } \\
\text { rived factor (PEDF) }\end{array}$ & wet AMD & [25] \\
\hline
\end{tabular}

$\mathrm{AAV}=$ adeno associate virus, $\mathrm{ADV}=$ adenovirus, $\mathrm{ADM}=$ age-related macular degeneration, $\mathrm{DR}=$ diabetic retinopathy, $\mathrm{LV}=$ lentivirus, $\mathrm{ROP}=$ retinopathy of prematurity

\section{Routes of administration for ocular gene therapy}

The ocular tissues can be reached by either local or systemic administration [3]. Eye has many tissue barriers that limit the access of drugs to theirs targets such as cornealand conjunctival epithelial -, blood-aqueous - and blood-retinal barriers. Especially bloodretina barrier limits drug diffusion from systemic circulation. Systemic administration has side effects such as systemic toxicity. Topical drug administration is non-invasive and easy to apply. It is used for the treatment of the anterior segment disorders. However, eye drops are ineffective to reach posterior tissues and have poor ocular bioavailability. Periocular, intracameral, intravitreal and subretinal administrations are invasive methods [7]. Periocular administration happens via peribulbar, retrobulbar, posterior juxtascleral, subtenon and subconjunctival injections. Subconjuctival injection is done between the bulbar conjunctiva and sclera and is a minimally invasive way to target the delivery of drugs to choroid and retina [102]. Subconjuctival injection of AAV vectors has shown to transduce the eyelid, conjunctiva, cornea, optic nerve and periocular tissues including muscle [103]. However, the injected drug might absorb to the lymphatic and blood circulation, which limits its ocular bioavailability [104]. Intracameral injection is done into the anterior chamber [105]. Intracameral injection of lentivirus vector has shown to transduce trabecular meshwork (TM) and corneal endothelial cells. AAV2, AAV3 and AAV4 cannot efficiently transduce TM [106]. Synthetically developed AAV, Anc80L65, has shown to transduce the anterior segment, including the TM, the corneal stroma, and endothelial cells. Self-complementary AAV2, scAAV5, and scAAV8 have shown to transduce the ciliary body, the iris, and corneal endothelium of the ocular hypertensive eyes [107]. The Intracameral injection might be an inefficient method because of the rapid turnover of aqueous humor and the short contact time with ocular tissues [102]. Suprachoroidal injection is done below the sclera and above choroid. It is minimally invasive and a simple way to target drugs to the posterior segment of the eye. Subrachoroidal AAV8 vector injection was shown to transduce retina and RPE [49]. Injection into suprachoroidal space does not interfere in the optical pathways however, macromolecules are cleared rapidly [7].

In pre-clinical trials, the subretinal injections are delivered by the transcorneal route through the pupil passing lens and retina, by the trans-scleral route through vitreous and by the trans-scleral route through the choroid and Bruch's membrane [108]. Whereas for humans, the subretinal injection can use pars plana vitrectomy approach in which core vitreous is removed $[109,110]$. A needle is guided into subretinal space and a bleb is formed by a small infusion of balanced salt solution. For gene delivery, the same injection channel through the neural retina is used to inject the therapeutic agent into the subretinal space. Compared with direct delivery into the subretinal space, this approach offers better access to the correct plane as well as minimizes vector loss but also exposes to surgical 
complications. Subretinal AAV2 and AAV5 injection have shown to transduce photoreceptor and RPE cells in the murine retina [27]. Subretinal injection is done into subretinal space and might cause ocular damage such as lesions, hemorrhages, fibrosis and retinal detachment [7]. Subretinal AAV transduction profile of photoreceptors differs significantly between neonatal and adult mouse retinas [111]. Photoreceptor development and integrity play a major role in the efficacy of surbretinal AAV-mediated transduction. It was shown that rod outer segments are critical modulators of efficient rod transduction, which increases during mouse postnatal retinal development. The loss of rod outer segments in diseased retinas affected the efficacy of gene transfer by limiting the ability of AAVs to infect dying rods efficiently. The altered development of rod outer segments was associated with an increase in transduced number of cones and a strong reduction of rod transduction. To achieve the best transduction efficiency in photoreceptor cells the timing of the treatment is to be considered.

Intravitreal administration is done into the vitreous [7]. Compared with subretinal injection, administration to vitreous is relatively easy and high doses are possible. The intravitreal injection route is directly applicable to patients and it is routinely used to administer ophthalmic drugs. As subretinal injections need to be performed in an operating theater, intravitreal injections are less invasive and less expensive [109]. However, it might have adverse effects such as retinal detachment, endophthalmitis and an increase in intraocular pressure [112]. Compared with the other intraocular injections, the intravitreal approach may be more efficient route for therapeutic gene delivery as it can potentially expose the entire retina [112] although it mostly targets cells in the inner retina [113-115] and anterior chamber $[21,116,117]$. It is important to consider which delivery route to choose to get efficient gene expression where it is needed.

\section{Discussion}

As VEGF is the main factor in ocular neovascularization, it is one of the most important targets in anti-angiogenic treatment [2]. Because VEGF, VEGFR-1, and VEGFR-2 are constitutively expressed in the eye, it is possible that the pharmacologic inhibition of VEGF bioactivity may have adverse consequences. VEGF is necessary for the maintenance of RPE and choriocapillaris [118]. CATT and IVAN clinical trials showed that monthly anti-VEGF therapy increased the risk of RPE atrophy. It is thought that Anti-VEGF therapy with bevacizumab for ROP delays and/or halts normal retinal vascularization. In one study, it was shown that low doses of bevancizumab had a good retinal structural outcome [119]. More future studies are under way to test lower doses of bevacizumab, which may possibly enhance normal retinal vascularization while posing less systemic risk [75]. Regardless of that extended follow-up is needed for infants. In one study, it was shown that anti-VEGF therapy suppresses serum VEGF levels. The lowering serum VEGF levels raises the concerns of the effects on the developing organs such as brain and lungs. However, none of the controlled studies has shown worse neural developmental outcomes in two years of age after intravitreal anti-VEGF treatment. In addition, despite possible concerns with biological anti-VEGF treatments, intraocular anti-angiogenic gene therapy has not shown any effect to serum VEGF levels 52 weeks post gene transfer [120] [30].

Pre-existing immunity to the adeno-associated virus (AAV) is highly prevalent in humans [121]. A relatively large portion of humans carry circulating antibodies against the AAV-capsid and these neutralizing antibodies may prevent AAV vector transduction and transgene expression. Natural exposure to different AAV serotypes can result in production of different IgG subclass antibodies [122]. The highest neutralizing factor prevalence was observed with AAV2 and AAV1. It is possible to use other AAV-serotype to overcome this problem. Although existing neutralizing antibodies to AAV, it was shown that second administration of AAV2 vector expressing RPE65 gene into subretinal space in individuals with herited retinal dystrophy to the second eye after previous exposure to AAV2 was safe and effective [123]. It has also shown in antiangiogenic gene therapies that 
AAV2 transduction does not appear to be altered to the same degree by pre-existing serum antibodies to AAV when the vectors are delivered in the subretinal space [96] [120]. This is considered to be related to the relative degree of immune privilege in the subretinal space compared with the vitreous [95].

The use of proper model organisms helps in studying treatments for ocular human diseases [124]. Bigger animal models such as primates for ocular diseases, particularly retinal diseases, could be more suitable for these purposes because they have macula in the like humans. However, these animals are expensive, genetically hard to manipulate and ethical concerns have to take into account. Rodents, especially mice, have become the most widely used model of different human diseases and ocular diseases even though mice and human eye and retina differ. Out of the 18 pre-clinical studies discussed here, 12 utilized mouse as test animal. Rabbits, primates and rats were used in a few studies. Mice are easy to manage, genetically manipulate and quite cheap. Gene transfer efficiency is usually inversely related to host size [125]. Generally, several applications and vector systems work in mice but obtaining equal treatment efficacy in larger animals and humans is the more difficult due limited tissue diffusion of the gene transfer vectors and larger volumes of the transfected tissues. When targeting eyes with gene transfer, this can be overcome relatively easily as it is small in size and target cells in the eye are reachable. In pre-clinical animal studies and clinical trials both subretinal and intravitreal administration routes were mostly used. Only exception are RGX-314 trials, which used injection into suprachoroidal space both in rodent [49] and in human trials [91, 93].

The number of patients in the phase 1 and 2 studies is low. In the on-going clinical trials of gene therapy for ocular neovascularization, the estimated number of participants is between 17 and 42 people (ClinicalTrials.gov, 2020i, 2020h). A small number of participants could lead more easily to variability between research subjects and carry a risk of failing to prove the effectiveness of the study treatment. In addition, the primary objective of the phase 1 studies are to assess the safety and tolerability. Thus, visual improvement is not the intended main outcome. In phase 1 trials, the need to avoid patients with good visual potential who stand to benefit from standard care, leads to situation in which participants have typically already severe vision impairment and they have failed to improve or maintain vision on existing standard treatments. As several clinical trials in AMD patients have shown a poor response or resistance to anti-VEGF treatment over time $[126,127]$, it can be speculated whether these kind of patients are able to demonstrate the efficacy of the gene therapy.

In conclusion, the preclinical animal studies have shown promising results with antiangiogenic gene therapy with viral vectors. Different serotypes of viruses have shown to transduce ocular tissues efficiently and by modifying vector design it can be further improved. Anti-angiogenic therapies have shown to be safe and well tolerated and reduce angiogenesis significantly. While pre-clinical studies succeeded, clinical trials haven't proceeded as fast. Different animal models, gene delivery methods, viral vector designs and timing of the treatment must be studied more to succeed also in clinical trials.

Despite years of clinical trials for ocular neovascular diseases, the studies have not yet proceeded to phase 3 studies. However, in 2017 FDA approved a subretinal delivery of AAV2-mediated voretigene neparvovec-rzyl (Luxturna ${ }^{\circledR}$ ) for the treatment of inherited biallelic RPE65 mutation-associated retinal dystrophy [8]. Luxturna ${ }^{\circledR}$ delivers a normal copy of the gene encoding the retinal pigment epithelial $65 \mathrm{kDa}$ protein to retinal cells [128]. Although Luxturna ${ }^{\circledR}$ is intended to treat a single gene mutation, the approval of the gene therapy proves that it is a usable tool for treating ocular diseases.

To conclude, the clinical trials of intraocular gene therapy for neovascularization have shown the treatment to be safe without severe adverse events or systemic effects. However, given the small number of participants and the nature of the early phase trials, they remain unable to unequivocally confirm the existence of gene therapy efficacy. Thus, after proven safety, bigger clinical trials with randomized controlled groups are needed to prove the biological effect in ocular neovascularization of the gene therapy treatments. 


\begin{abstract}
Author Contributions Conceptualization, S.Y-H.; resources, S.Y-H.; writing-original draft preparation, S.K., E.K.; writing - review and editing, S.K., E.K.; visualization, S.K., E.K.; supervision, K.K., S.Y-H.; funding acquisition, S.Y-H. All authors have read and agreed to the published version of the manuscript.
\end{abstract}

Funding: This review was supported by grants from Finnish Academy and Sigrid Juselius Foundation

Conflicts of Interest: The authors declare no conflict of interest

\title{
References
}

1. Liu, C.H.; Wang, Z.; Sun, Y.; Chen, J. Animal models of ocular angiogenesis: From development to pathologies. FASEB J. 2017, 31, 4665-4681, doi:10.1096/fj.201700336R.

2. Kim, I.; Ryan, A.M.; Rohan, R.; Amano, S.; Agular, S.; Miller, J.W.; Adamis, A.P. Constitutive Expression of VEGF, VEGFR-1, and VEGFR-2 in Normal Eyes. Invest. Ophthalmol. 2016, 40, 2115-2121.

3. del Amo, E.M.; Urtti, A. Current and future ophthalmic drug delivery systems. A shift to the posterior segment. Drug Discov. Today 2008, 13, 135-143, doi:10.1016/j.drudis.2007.11.002.

4. Wykoff, C.C.; Clark, W.L.; Nielsen, J.S.; Brill, J. V; Greene, L.S.; Heggen, C.L. Optimizing Anti-VEGF Treatment Outcomes for Patients with Neovascular Age-Related Macular Degeneration. J. Manag. care Spec. Pharm. 2018, 24, S3-S15.

5. Ylä-Herttuala, S.; Bridges, C.; Katz, M.G.; Korpisalo, P. Angiogenic gene therapy in cardiovascular diseases: Dream or vision? Eur. Heart J. 2017, 38, 1365-1371.

6. Kalesnykas, G.; Kokki, E.; Alasaarela, L.; Lesch, H.P.; Tuulos, T.; Kinnunen, K.; Uusitalo, H.; Airenne, K.; YlaHerttuala, S. Comparative Study of Adeno-associated Virus, Adenovirus, Bacu lovirus and Lentivirus Vectors for Gene Therapy of the Eyes. Curr. Gene Ther. 2017, 17, 235-247, doi:10.2174/1566523217666171003170348.

7. Solinís, M.Á.; Del Pozo-Rodríguez, A.; Apaolaza, P.S.; Rodríguez-Gascón, A. Treatment of ocular disorders by gene therapy. Eur. J. Pharm. Biopharm. 2015, 95, 331-342.

8. Ameri, H. Prospect of retinal gene therapy following commercialization of voretigene neparvovec-rzyl for retinal dystrophy mediated by RPE65 mutation. J. Curr. Ophthalmol. 2018, 30, 1-2, doi:10.1016/j.joco.2018.01.006.

9. Hoeben, A.; Landuyt, B.; Highley, M.S.; Wildiers, H.; Van Oosterom, A.T.; De Bruijn, E.A. Vascular endothelial growth factor and angiogenesis. Pharmacol. Rev. 2004, 56, 549-580.

10. Ylä-Herttuala, S.; Rissanen, T.T.; Vajanto, I.; Hartikainen, J. Vascular Endothelial Growth Factors. Biology and Current Status of Clinical Applications in Cardiovascular Medicine. J. Am. Coll. Cardiol. 2007, 49, 1015-1026, doi:10.1016/j.jacc.2006.09.053.

11. Vuorio, T.; Jauhiainen, S.; Ylä-Herttuala, S. Pro- and anti-angiogenic therapy and atherosclerosis with special emphasis on vascular endothelial growth factors. Expert Opin. Biol. Ther. 2012, 12, 79-92, doi:10.1517/14712598.2012.641011.

12. Carmeliet, P.; Jain, R.K. Molecular mechanisms and clinical applications of angiogenesis. Nature 2011, 473, 298307, doi:10.1038/nature10144.

13. Sene, A.; Chin-Yee, D.; Apte, R.S. Seeing through VEGF: Innate and adaptive immunity in pathological angiogenesis in the eye. Trends Mol. Med. 2015, 21, 43-51, doi:10.1016/j.molmed.2014.10.005.

14. Al-Zamil, W.M.; Yassin, S.A. Recent developments in age-related macular degeneration: A review. Clin. Interv. Aging 2017, 12.

15. Zhao, Y.; Singh, R.P. The role of anti-vascular endothelial growth factor (anti-VEGF) in the management of proliferative diabetic retinopathy. Drugs Context 2018, 7, 212532. 
16. Avastin I European Aedicines Agency online: https://www.ema.europa.eu/en/medicines/human/EPAR/avastin\#overview-section (accessed on Nov 27, 2020).

17. Cotrim, A.P.; Baum, B.J. Gene Therapy: Some History, Applications, Problems, and Prospects. Toxicol. Pathol. 2008, 36, 97-103, doi:10.1177/0192623307309925.

18. Oliveira, A. V; Rosa da Costa, A.M.; Silva, G.A. Non-viral strategies for ocular gene delivery. Mater. Sci. Eng. C 2017, 77, 1275-1289.

19. Rissanen, T.T.; Ylä-Herttuala, S. Current Status of Cardiovascular Gene Therapy. 2007, doi:10.1038/sj.mt.6300175.

20. Volpers, C.; Kochanek, S. Adenoviral vectors for gene transfer and therapy. J. Gene Med. 2004, 6, S164-S171, doi:10.1002/jgm.496.

21. Ueyama, K.; Mori, K.; Shoji, T.; Omata, H.; Gehlbach, P.L.; Brough, D.E.; Wei, L.L.; Yoneya, S. Ocular localization and transduction by adenoviral vectors are serotype-dependent and can be modified by inclusion of rgd fiber modifications. PLoS One 2014, 9, doi:10.1371/journal.pone.0108071.

22. Kinnunen, K.; Kalesnykas, G.; Mähönen, A.J.; Laidinen, S.; Holma, L.; Heikura, T.; Airenne, K.; Uusitalo, H.; YläHerttuala, S. Baculovirus is an efficient vector for the transduction of the eye: comparison of baculovirus- and adenovirus-mediated intravitreal vascular endothelial growth factor D gene transfer in the rabbit eye. J. Gene Med. 2009, 11, 382-389, doi:10.1002/jgm.1311.

23. Hamilton, M.M.; Byrnes, G.A.; Gall, J.G.; Brough, D.E.; King, C.R.; Wei, L.L. Alternate serotype adenovector provides long-term therapeutic gene expression in the eye. Mol. Vis. 2008, 14, 2535-2546.

24. Ildefonso, C.J.; Kong, L.; Leen, A.; Chai, S.J.; Petrochelli, V.; Chintagumpala, M.; Hurwitz, M.Y.; Chévez-Barrios, P.; Hurwitz, R.L. Absence of systemic immune response to adenovectors after intraocular administration to children with retinoblastoma. Mol. Ther. 2010, 18, 1885-1890, doi:10.1038/mt.2010.139.

25. Campochiaro, P.A.; Nguyen, Q.D.; Shah, S.M.; Klein, M.L.; Holz, E.; Frank, R.N.; Saperstein, D.A.; Gupta, A.; Stout, J.T.; Macko, J.; et al. Adenoviral Vector-Delivered Pigment Epithelium-Derived Factor for Neovascular Age-Related Macular Degeneration: Results of a Phase I Clinical Trial. Hum. Gene Ther. 2006, 17, 167-176, doi:10.1089/hum.2006.17.167.

26. Deyle, D.R.; Russell, D.W. Adeno-associated virus vector integration. Curr. Opin. Mol. Ther. 2009, 11, $442-447$.

27. Yang, G.S.; Schmidt, M.; Yan, Z.; Lindbloom, J.D.; Harding, T.C.; Donahue, B.A.; Engelhardt, J.F.; Kotin, R.; Davidson, B.L. Virus-Mediated Transduction of Murine Retina with Adeno-Associated Virus: Effects of Viral Capsid and Genome Size. J. Virol. 2002, 76, 7651-7660, doi:10.1128/jvi.76.15.7651-7660.2002.

28. MacLachlan, T.K.; Lukason, M.; Collins, M.; Munger, R.; Isenberger, E.; Rogers, C.; Malatos, S.; Dufresne, E.; Morris, J.; Calcedo, R.; et al. Preclinical safety evaluation of AAV2-sFLT01 a gene therapy for age-related macular degeneration. Mol. Ther. 2011, 19, 326-334, doi:10.1038/mt.2010.258.

29. Ye, G.J.; Conlon, T.; Erger, K.; Sonnentag, P.; Sharma, A.K.; Howard, K.; Knop, D.R.; Chulay, J.D. Safety and Biodistribution Evaluation of rAAV2tYF-CB-hRS1, a Recombinant Adeno-Associated Virus Vector Expressing Retinoschisin, in RS1-Deficient Mice. Hum. Gene Ther. Clin. Dev. 2015, 26, 177-184, doi:10.1089/humc.2015.077.

30. Constable, I.J.; Pierce, C.M.; Lai, C.-M.M.; Magno, A.L.; Degli-Esposti, M.A.; French, M.A.; McAllister, I.L.; Butler, S.; Barone, S.B.; Schwartz, S.D.; et al. Phase 2a Randomized Clinical Trial: Safety and Post Hoc Analysis of Subretinal rAAV.sFLT-1 for Wet Age-related Macular Degeneration. EBioMedicine 2016, 14, 168-175, doi:10.1016/j.ebiom.2016.11.016.

31. Maguire, A.M.; High, K.A.; Auricchio, A.; Wright, J.F.; Pierce, E.A.; Testa, F.; Mingozzi, F.; Bennicelli, J.L.; Ying, G. shuang; Rossi, S.; et al. Age-dependent effects of RPE65 gene therapy for Leber's congenital amaurosis: a phase 1 dose-escalation trial. Lancet 2009, 374, 1597-1605, doi:10.1016/S0140-6736(09)61836-5.

32. Bennett, J.; Wellman, J.; Marshall, K.A.; McCague, S.; Ashtari, M.; DiStefano-Pappas, J.; Elci, O.U.; Chung, D.C.; 
Sun, J.; Wright, J.F.; et al. Safety and durability of effect of contralateral-eye administration of AAV2 gene therapy in patients with childhood-onset blindness caused by RPE65 mutations: a follow-on phase 1 trial. Lancet 2016, 388, 661-672, doi:10.1016/S0140-6736(16)30371-3.

33. Cukras, C.; Wiley, H.E.; Jeffrey, B.G.; Sen, H.N.; Turriff, A.; Zeng, Y.; Vijayasarathy, C.; Marangoni, D.; Ziccardi, L.; Kjellstrom, S.; et al. Retinal AAV8-RS1 Gene Therapy for X-Linked Retinoschisis: Initial Findings from a Phase I/IIa Trial by Intravitreal Delivery. Mol. Ther. 2018, 26, 2282-2294, doi:10.1016/j.ymthe.2018.05.025.

34. Worgall, S.; Crystal, R.G. Gene Therapy; Fourth Edi.; Elsevier, 2013; ISBN 9780123983589.

35. Vargas, J.E.; Chicaybam, L.; Stein, R.T.; Tanuri, A.; Delgado-Cañedo, A.; Bonamino, M.H. Retroviral vectors and transposons for stable gene therapy: Advances, current challenges and perspectives. J. Transl. Med. 2016, 14, 288.

36. Hacein-Bey-Abina, S.; Garrigue, A.; Wang, G.P.; Soulier, J.; Lim, A.; Morillon, E.; Clappier, E.; Caccavelli, L.; Delabesse, E.; Beldjord, K.; et al. Insertional oncogenesis in 4 patients after retrovirus-mediated gene therapy of SCID-X1. J. Clin. Invest. 2008, 9, 3132-3142, doi:10.1172/JCI35700.3132.

37. Askou, A.L.; Benckendorff, J.N.E.; Holmgaard, A.; Storm, T.; Aagaard, L.; Bek, T.; Mikkelsen, J.G.; Corydon, T.J. Suppression of Choroidal Neovascularization in Mice by Subretinal Delivery of Multigenic Lentiviral Vectors Encoding Anti-Angiogenic MicroRNAs. Hum. Gene Ther. Methods 2017, 28, 222-233, doi:10.1089/hgtb.2017.079.

38. Bemelmans, A.P.; Bonnel, S.; Houhou, L.; Dufour, N.; Nandrot, E.; Helmlinger, D.; Sarkis, C.; Abitbol, M.; Mallet, J. Retinal cell type expression specificity of HIV-1-derived gene transfer vectors upon subretinal injection in the adult rat: Influence of pseudotyping and promoter. J. Gene Med. 2005, 7, 1367-1374, doi:10.1002/jgm.788.

39. Cheng, L.; Chaidhawangul, S.; Wong-Staal, F.; Gilbert, J.; Poeschla, E.; Toyoguchi, M.; El-Bradey, M.H.; Bergeron-Lynn, G.; Soules, K.A.; Freeman, W.R. Human immunodeficiency virus type 2 (HIV-2) vectormediated in vivo gene transfer into adult rabbit retina. Curr. Eye Res. 2002, 24, 196-201, doi:10.1076/ceyr.24.3.196.8302.

40. Ikeda, Y.; Yonemitsu, Y.; Miyazaki, M.; Kohno, R.I.; Murakami, Y.; Murata, T.; Goto, Y.; Tabata, T.; Ueda, Y.; Ono, F.; et al. Acute toxicity study of a simian immunodeficiency virus-based lentiviral vector for retinal gene transfer in nonhuman primates. Hum. Gene Ther. 2009, 20, 943-954, doi:10.1089/hum.2009.048.

41. Matet, A.; Kostic, C.; Bemelmans, A.-P.; Moulin, A.; Rosolen, S.G.; Martin, S.; Mavilio, F.; Amirjanians, V.; Stieger, K.; Lorenz, B.; et al. Evaluation of tolerance to lentiviral LV-RPE65 gene therapy vector after subretinal delivery in non-human primates. Transl. Res. 2017, 188, 40-57.e4, doi:10.1016/J.TRSL.2017.06.012.

42. Campochiaro, P.A.; Lauer, A.K.; Sohn, E.H.; Mir, T.A.; Naylor, S.; Anderton, M.C.; Kelleher, M.; Harrop, R.; Ellis, S.; Mitrophanous, K.A. Lentiviral vector gene transfer of endostatin/angiostatin for macular degeneration (GEM) study. Hum. Gene Ther. 2017, 28, 99-111, doi:10.1089/hum.2016.117.

43. Ono, C.; Okamoto, T.; Abe, T.; Matsuura, Y. Baculovirus as a tool for gene delivery and gene therapy. Viruses 2018, 10 .

44. Haeseleer, F.; Imanishi, Y.; Saperstein, D.A.; Palczewski, K. Gene transfer mediated by recombinant baculovirus into mouse eye. Investig. Ophthalmol. Vis. Sci. 2001, 42, 3294-3300.

45. Reid, C.A.; Nettesheim, E.R.; Connor, T.B.; Lipinski, D.M. Development of an inducible anti-VEGF rAAV gene therapy strategy for the treatment of wet AMD. 2018, 8, 11763, doi:10.1038/s41598-018-29726-7.

46. Pavlova, N.; Kaloudas, D.; Penchovsky, R. Riboswitch distribution, structure, and function in bacteria. Gene 2019, 708, 38-48.

47. Grishanin, R.; Vuillemenot, B.; Sharma, P.; Keravala, A.; Greengard, J.; Gelfman, C.; Blumenkrantz, M.; Lawrence, M.; Hu, W.; Kiss, S.; et al. Preclinical Evaluation of ADVM-022, a Novel Gene Therapy Approach to Treating Wet Age-Related Macular Degeneration. Mol. Ther. 2019, 27, 118-129, doi:10.1016/j.ymthe.2018.11.003.

48. Hughes, C.P.; O’Flynn, N.M.J.; Gatherer, M.; McClements, M.E.; Scott, J.A.; MacLaren, R.E.; Goverdhan, S.; 
Glennie, M.J.; Lotery, A.J. AAV2/8 Anti-angiogenic Gene Therapy Using Single-Chain Antibodies Inhibits Murine Choroidal Neovascularization. Mol. Ther. - Methods Clin. Dev. 2019, 13, 86-98, doi:10.1016/j.omtm.2018.11.005.

49. Ding, K.; Shen, J.; Hafiz, Z.; Hackett, S.F.; e Silva, R.L.; Khan, M.; Lorenc, V.E.; Chen, D.; Chadha, R.; Zhang, M.; et al. AAV8-vectored suprachoroidal gene transfer produces widespread ocular transgene expression. J. Clin. Invest. 2019, 129, 4901-4911, doi:10.1172/JCI129085.

50. Liu, Y.; Fortmann, S.D.; Shen, J.; Wielechowski, E.; Tretiakova, A.; Yoo, S.; Kozarsky, K.; Wang, J.; Wilson, J.M.; Campochiaro, P.A. AAV8-antiVEGFfab Ocular Gene Transfer for Neovascular Age-Related Macular Degeneration. Mol. Ther. 2018, 26, 542-549, doi:10.1016/j.ymthe.2017.12.002.

51. Lee, S.H.S.; Kim, H.J.; Shin, O.K.; Choi, J.S.; Kim, J.; Cho, Y.H.; Ha, J.; Park, T.K.; Lee, J.Y.; Park, K.; et al. Intravitreal injection of AAV expressing soluble VEGF receptor-1 variant induces anti-VEGF activity and suppresses choroidal neovascularization. Investig. Ophthalmol. Vis. Sci. 2018, 59, 5398-5407, doi:10.1167/iovs.1824926.

52. $\quad$ Park, T.K.; Lee, S.H.; Choi, J.S.; Nah, S.K.; Kim, H.J.; Park, H.Y.; Lee, H.; Lee, S.H.S.; Park, K. Adeno-Associated Viral Vector-Mediated mTOR Inhibition by Short Hairpin RNA Suppresses Laser-Induced Choroidal Neovascularization. Mol. Ther. - Nucleic Acids 2017, 8, 26-35, doi:10.1016/j.omtn.2017.05.012.

53. Lee, S.H.S.; Chang, H.S.; Kim, J.H.; Kim, H.J.; Choi, J.S.; Chung, S.; Woo, H.N.; Lee, K.J.; Park, K.; Lee, J.Y.; et al. Inhibition of mTOR via an AAV-delivered shRNA tested in a rat oir model as a potential antiangiogenic gene therapy. Investig. Ophthalmol. Vis. Sci. 2020, 61, doi:10.1167/iovs.61.2.45.

54. Lee, S.H.S.; Chang, H.S.; Kim, H.J.; Choi, J.S.; Kim, J.; Kim, J.H.; Woo, H.N.; Nah, S.K.; Jung, S.J.; Lee, J.Y.; et al. Effects of Stuffer DNA on the Suppression of Choroidal Neovascularization by a rAAV Expressing a mTORInhibiting shRNA. Mol. Ther. - Methods Clin. Dev. 2019, 14, 171-179, doi:10.1016/j.omtm.2019.06.004.

55. Abdollahi, I.A.; Hahnfeldt, P.; Maercker, C.; Grö, H.-J.; Debus, J.; Ansorge, W.; Folkman, J.; Hlatky, L. Endostatin's Antiangiogenic Signaling Network Endostatin, a $20 \mathrm{kDa}$ fragment of collagen XVIII, is a member of a group of endogenous antiangiogenic pro; 2004; Vol. 13;.

56. Mori, K.; Ando, A.; Gehlbach, P.; Nesbitt, D.; Takahashi, K.; Goldsteen, D.; Penn, M.; Chen, C.T.; Mori, K.; Melia, M.; et al. Inhibition of choroidal neovascularization by intravenous injection of adenoviral vectors expressing secretable endostatin. Am. J. Pathol. 2001, 159, 313-320, doi:10.1016/S0002-9440(10)61697-5.

57. Biswal, M.R.; Prentice, H.M.; Smith, G.W.; Zhu, P.; Tong, Y.; Dorey, \& C.K.; Lewin, A.S.; Blanks, J.C. Cell-specific gene therapy driven by an optimized hypoxia-regulated vector reduces choroidal neovascularization. J. Mol. Med. 2018, 96, 1107-1118, doi:10.1007/s00109-018-1683-0.

58. Bee, Y.S.; Ma, Y.L.; Chen, J.; Tsai, P.J.; Sheu, S.J.; Lin, H.C.; Huang, H.; Liu, G.S.; Tai, M.H. Inhibition of experimental choroidal neovascularization by a novel peptide derived from calreticulin anti-angiogenic domain. Int. J. Mol. Sci. 2018, 19, 2993, doi:10.3390/ijms19102993.

59. Tu, L.; Wang, J.H.; Barathi, V.A.; Prea, S.M.; He, Z.; Lee, J.H.; Bender, J.; King, A.E.; Logan, G.J.; Alexander, I.E.; et al. AAV-mediated gene delivery of the calreticulin anti-angiogenic domain inhibits ocular neovascularization. Angiogenesis 2018, 21, 95-109, doi:10.1007/s10456-017-9591-4.

60. Xin, X.; Yang, S.; Ingle, G.; Zlot, C.; Rangell, L.; Kowalski, J.; Schwall, R.; Ferrara, N.; Gerritsen, M.E. Hepatocyte growth factor enhances vascular endothelial growth factor-induced angiogenesis in vitro and in vivo. Am. J. Pathol. 2001, 158, 1111-1120, doi:10.1016/S0002-9440(10)64058-8.

61. Shen, Z.; Zhen, F.Y.; Gao, Y.; Ji, C.L.; Hai, X.C.; Ching, C.L.; Poon, R.T.; Sheung, T.F.; Luk, J.M.; Kong, H.S.; et al. The kringle 1 domain of hepatocyte growth factor has antiangiogenic and antitumor cell effects on hepatocellular carcinoma. Cancer Res. 2008, 68, 404-414, doi:10.1158/0008-5472.CAN-07-2081. 
62. Sun, P.; Liu, Z. Overexpressing kringle 1 domain of hepatocyte growth factor with adeno-associated virus inhibits the pathological retinal neovascularization in an oxygen-induced retinopathy mouse model. Biochem. Biophys. Res. Commun. 2019, 508, 130-137, doi:10.1016/j.bbrc.2018.11.111.

63. van Beijnum, J.R.; Thijssen, V.L.; Läppchen, T.; Wong, T.J.; Verel, I.; Engbersen, M.; Schulkens, I.A.; Rossin, R.; Grüll, H.; Griffioen, A.W.; et al. A key role for galectin-1 in sprouting angiogenesis revealed by novel rationally designed antibodies. Int. J. Cancer 2016, 139, 824-835, doi:10.1002/ijc.30131.

64. Abu El-Asrar, A.M.; Ahmad, A.; Allegaert, E.; Siddiquei, M.M.; Alam, K.; Gikandi, P.W.; De Hertogh, G.; Opdenakker, G. Galectin-1 studies in proliferative diabetic retinopathy. Acta Ophthalmol. 2020, 98, e1-e12, doi:10.1111/aos.14191.

65. Yang, N.; Zhang, W.; He, T.; Xing, Y. Silencing of galectin-1 inhibits retinal neovascularization and ameliorates retinal hypoxia in a murine model of oxygen-induced ischemic retinopathy. Exp. Eye Res. 2017, 159, 1-15, doi:10.1016/j.exer.2017.02.015.

66. Manghwar, H.; Lindsey, K.; Zhang, X.; Jin, S. CRISPR/Cas System: Recent Advances and Future Prospects for Genome Editing. Trends Plant Sci. 2019, 24, 1102-1125.

67. Huang, X.; Zhou, G.; Wu, W.; Duan, Y.; Ma, G.; Song, J.; Xiao, R.; Vandenberghe, L.; Zhang, F.; D' Amore, P.A.; et al. Genome editing abrogates angiogenesis in vivo. Nat. Commun. 2017, 8, doi:10.1038/s41467-017-00140-3.

68. Zetsche, B.; Gootenberg, J.S.; Abudayyeh, O.O.; Slaymaker, I.M.; Makarova, K.S.; Essletzbichler, P.; Volz, S.E.; Joung, J.; Van Der Oost, J.; Regev, A.; et al. Cpf1 Is a Single RNA-Guided Endonuclease of a Class 2 CRISPR-Cas System. Cell 2015, 163, 759-771, doi:10.1016/j.cell.2015.09.038.

69. Koo, T.; Park, S.W.; Jo, D.H.; Kim, D.; Kim, J.H.; Cho, H.-Y.; Kim, J.; Kim, J.H.; Kim, J.-S. CRISPR-LbCpf1 prevents choroidal neovascularization in a mouse model of age-related macular degeneration., doi:10.1038/s41467-01804175-y.

70. Askou, A.L.; Alsing, S.; Benckendorff, J.N.E.; Holmgaard, A.; Mikkelsen, J.G.; Aagaard, L.; Bek, T.; Corydon, T.J. Suppression of Choroidal Neovascularization by AAV-Based Dual-Acting Antiangiogenic Gene Therapy. Mol. Ther. - Nucleic Acids 2019, 16, 38-50, doi:10.1016/j.omtn.2019.01.012.

71. Park, K.; Jin, J.; Hu, Y.; Zhou, K.; Ma, J.X. Overexpression of pigment epithelium-derived factor inhibits retinal inflammation and neovascularization. Am. J. Pathol. 2011, 178, 688-698, doi:10.1016/j.ajpath.2010.10.014.

72. Hirsch, M.L.; Conatser, L.M.; Smith, S.M.; Salmon, J.H.; Wu, J.; Buglak, N.E.; Davis, R.; Gilger, B.C. AAV vectormeditated expression of HLA-G reduces injury-induced corneal vascularization, immune cell infiltration, and fibrosis. 2017, 7, 17840, doi:10.1038/s41598-017-18002-9.

73. Carosella, E.D.; Rouas-Freiss, N.; Roux, D.T. Le; Moreau, P.; LeMaoult, J. HLA-G. An Immune Checkpoint Molecule.; 1st ed.; Elsevier Inc., 2015; Vol. 127; ISBN 9780128022450.

74. Le Discorde, M.; Moreau, P.; Sabatier, P.; Legeais, J.M.; Carosella, E.D. Expression of HLA-G in Human Cornea, an Immune-Privileged Tissue. In Proceedings of the Human Immunology; 2003; Vol. 64, pp. 1039-1044.

75. VanderVeen, D.K.; Cataltepe, S.U. Anti-vascular endothelial growth factor intravitreal therapy for retinopathy of prematurity. Semin. Perinatol. 2019, 43, 375-380.

76. Simmons, A.B.; Bretz, C.A.; Wang, H.; Kunz, E.; Hajj, K.; Kennedy, C.; Yang, Z.; Suwanmanee, T.; Kafri, T.; Hartnett, M.E. Gene therapy knockdown of VEGFR2 in retinal endothelial cells to treat retinopathy. Angiogenesis 2018, 21, 751-764, doi:10.1007/s10456-018-9618-5.

77. Becker, S.; Wang, H.; Simmons, A.B.; Suwanmanee, T.; Stoddard, G.J.; Kafri, T.; Elizabeth Hartnett, M. Targeted Knockdown of Overexpressed VEGFA or VEGF164 in Müller cells maintains retinal function by triggering different signaling mechanisms. Sci. Rep. 2018, 8, 1-13, doi:10.1038/s41598-018-20278-4.

78. Wiley database on Gene Therapy Trials Worldwide Gene Therapy Clinical Trials Worldwide Available online: 
http://www.abedia.com/wiley/indications.php (accessed on Sep 13, 2020).

79. Farkas, I.; Baranyi, L.; Ishikawa, Y.; Okada, N.; Bohata, C.; Budai, D.; Fukuda, A.; Imai, M.; Okada, H. CD59 blocks not only the insertion of $\mathrm{C} 9$ into MAC but inhibits ion channel formation by homologous C5b-8 as well as C5b-9. J. Physiol. 2002, 539, 537-45, doi:10.1113/JPHYSIOL.2001.013381.

80. Hageman, G.S.; Anderson, D.H.; Johnson, L. V; Hancox, L.S.; Taiber, A.J.; Hardisty, L.I.; Hageman, J.L.; Stockman, H.A.; Borchardt, J.D.; Gehrs, K.M.; et al. A common haplotype in the complement regulatory gene factor H (HF1/CFH) predisposes individuals to age-related macular degeneration. Proc. Natl. Acad. Sci. U. S. A. 2005, 102, 7227-7232, doi:10.1073/pnas.0501536102.

81. Ebrahimi, K.B.; Fijalkowski, N.; Cano, M.; Handa, J.T. Decreased membrane complement regulators in the retinal pigmented epithelium contributes to age-related macular degeneration. J. Pathol. 2013, 229, 729-742, doi:10.1002/path.4128.

82. Singh, A.; Faber, C.; Falk, M.; Nissen, M.H.; Hviid, T.V.F.; Sørensen, T.L. Altered expression of CD46 and CD59 on leukocytes in neovascular age-related macular degeneration. Am. J. Ophthalmol. 2012, 154, 193-199, doi:10.1016/j.ajo.2012.01.036.

83. ClinicalTrials.gov AAVCAGsCD59 for the Treatment of Wet AMD Available online: https://clinicaltrials.gov/ct2/show/study/NCT03585556?cond=gene+therapy+eye\&draw=6\&rank=47 (accessed on Sep 13, 2020).

84. ClinicalTrials.gov ADVM-022 Intravitreal Gene Therapy for Wet AMD Available online: https://clinicaltrials.gov/ct2/show/NCT03748784?cond=gene+therapy+eye\&draw=3\&rank=15 (accessed on Sep 13, 2020).

85. ClinicalTrials.gov ADVM-022 Intravitreal Gene Therapy for DME Available online: https://clinicaltrials.gov/ct2/show/NCT04418427?cond=gene+therapy+retina\&draw=3\&rank=20 (accessed on Sep 13, 2020).

86. Globe Newswire Adverum Biotechnologies Announces Positive Interim Data from Cohorts 1-4 from OPTIC Phase 1 Trial of ADVM-022 Intravitreal Gene Therapy for wet AMD, Reports Recent Business Progress and Second Quarter 2020 Financial Results Available online: https://www.globenewswire.com/newsrelease/2020/08/10/2075903/0/en/Adverum-Biotechnologies-Announces-Positive-Interim-Data-from-Cohorts-14-from-OPTIC-Phase-1-Trial-of-ADVM-022-Intravitreal-Gene-Therapy-for-wet-AMD-Reports-RecentBusiness-Progress.html (accessed on Nov 12, 2020).

87. Globe Newswire Adverum Biotechnologies Announces New INFINITY Phase 2 Trial for ADVM-022 in Diabetic Macular Edema, Reports Recent Business Progress and First Quarter 2020 Financial Results Available online: https://www.globenewswire.com/news-release/2020/05/28/2040528/0/en/Adverum-Biotechnologies-

Announces-New-INFINITY-Phase-2-Trial-for-ADVM-022-in-Diabetic-Macular-Edema-Reports-RecentBusiness-Progress-and-First-Quarter-2020-Financial-Results.html (accessed on Nov 15, 2020).

88. ClinicalTrials.gov RGX-314 Gene Therapy for Neovascular AMD Trial Available online: https://clinicaltrials.gov/ct2/show/NCT03066258?cond=gene+therapy+eye\&draw=3\&rank=12 (accessed on Sep 13, 2020).

89. ClinicalTrials.gov Long-term Follow-Up Study of RGX-314 Available online: https://clinicaltrials.gov/ct2/show/NCT03999801?cond=gene+therapy+retina\&draw=5\&rank=33 (accessed on Sep 13, 2020).

90. Eyewire news Regenxbio Announces Additional Positive Long-Term and Interim Phase 1/2a Trial Update for RGX-314 for the Treatment of Wet AMD Available online: https://eyewire.news/articles/regenxbio-announcesadditional-positive-long-term-and-interim-phase-1-2a-trial-update-for-rgx-314-for-the-treatment-of-wet-amd/ 
(accessed on Sep 13, 2020).

91. ClinicalTrials.gov RGX-314 Gene Therapy Administered in the Suprachoroidal Space for Participants With Neovascular Age-Related Macular Degeneration (nAMD) Available online: https:/clinicaltrials.gov/ct2/show/NCT04514653?cond=gene+therapy\%2C+amd\&draw=2\&rank=2 (accessed on Sep 13, 2020).

92. Modern Retina Staff Reports Regenxbio: Dosing of first patient in Phase 2 AAVIATE trial for wet AMD I Modern Retina Available online: https://www.modernretina.com/view/regenxbio-dosing-of-first-patient-in-phase-2aaviate-trial-for-wet-amd (accessed on Nov 12, 2020).

93. ClinicalTrials.gov RGX-314 Gene Therapy Administered in the Suprachoroidal Space for Participants With Diabetic Retinopathy (DR) Without Center Involved-Diabetic Macular Edema (CI-DME) Available online: https://clinicaltrials.gov/ct2/show/NCT04567550?term=RGX-314\&draw=2\&rank=2 (accessed on Nov 12, 2020).

94. Failla, C.M.; Carbo, M.; Morea, V. Positive and negative regulation of angiogenesis by soluble vascular endothelial growth factor receptor-1. Int. J. Mol. Sci. 2018, 19.

95. Rakoczy, E.P.; Magno, A.L.; Lai, C.M.; Pierce, C.M.; Degli-Esposti, M.A.; Blumenkranz, M.S.; Constable, I.J. Three-Year Follow-Up of Phase 1 and 2a rAAV.sFLT-1 Subretinal Gene Therapy Trials for Exudative AgeRelated Macular Degeneration. Am. J. Ophthalmol. 2019, 204, 113-123, doi:10.1016/j.ajo.2019.03.006.

96. Heier, J.S.; Kherani, S.; Desai, S.; Dugel, P.; Kaushal, S.; Cheng, S.H.; Delacono, C.; Purvis, A.; Richards, S.; LeHalpere, A.; et al. Intravitreous injection of AAV2-sFLT01 in patients with advanced neovascular age-related macular degeneration: a phase 1, open-label trial. Lancet 2017, 390, doi:10.1016/S0140-6736(17)30979-0.

97. Tombran-Tink, J.; Chader, G.G.; Johnson, L. V. PEDF: A pigment epithelium-derived factor with potent neuronal differentiative activity. Exp. Eye Res. 1991, 53, 411-414.

98. Ogata, N.; Nishikawa, M.; Nishimura, T.; Mitsuma, Y.; Matsumura, M. Unbalanced vitreous levels of pigment epithelium-derived factor and vascular endothelial growth factor in diabetic retinopathy. Am. J. Ophthalmol. 2002, 134, 348-353, doi:10.1016/S0002-9394(02)01568-4.

99. Ogata, N.; Tombran-Tink, J.; Nishikawa, M.; Nishimura, T.; Mitsuma, Y.; Sakamoto, T.; Matsumura, M. Pigment epithelium-derived factor in the vitreous is low in diabetic retinopathy and high in rhegmatogenous retinal detachment. Am. J. Ophthalmol. 2001, 132, 378-382, doi:10.1016/S0002-9394(01)01008-X.

100. Holekamp, N.M.; Bouck, N.; Volpert, O. Pigment Epithelium-derived Factor Is Deficient in the Vitreous of Patients With Choroidal Neovascularization due to Age-related Macular Degeneration. Am. J. Ophthalmol. 2002, 134, 220-227, doi:10.1016/S0002-9394(02)01549-0.

101. Ohno-Matsui, K.; Morita, I.; Tombran-Tink, J.; Mrazek, D.; Onodera, M.; Uetama, T.; Hayano, M.; Murota, S.; Mochizuki, M. Novel mechanism for age-related macular degeneration: An equilibrium shift between the angiogenesis factors VEGF and PEDF. J. Cell. Physiol. 2001, 189, 323-333, doi:10.1002/jcp.10026.

102. Patel, S.R.; Berezovsky, D.E.; McCarey, B.E.; Zarnitsyn, V.; Edelhauser, H.F.; Prausnitz, M.R. Targeted administration into the suprachoroidal space using a microneedle for drug delivery to the posterior segment of the eye. Investig. Ophthalmol. Vis. Sci. 2012, 53, 4433-4441, doi:10.1167/iovs.12-9872.

103. Song, L.; Llanga, T.; Conatser, L.M.; Zaric, V.; Gilger, B.C.; Hirsch, M.L. Serotype survey of AAV gene delivery via subconjunctival injection in mice. Gene Ther. 2018, 25, 402-414, doi:10.1038/s41434-018-0035-6.

104. Subrizi, A.; del Amo, E.M.; Korzhikov-Vlakh, V.; Tennikova, T.; Ruponen, M.; Urtti, A. Design principles of ocular drug delivery systems: importance of drug payload, release rate, and material properties. Drug Discov. Today 2019, doi:10.1016/J.DRUDIS.2019.02.001.

105. Challa, P.; Luna, C.; Liton, P.B.; Chamblin, B.S.; Wakefiled, J.K.; Ramabhadran, R.; Epstein, D.L.; Gonzalez, P. Lentiviral mediated gene delivery to the anterior chamber of rodent eyes. Mol. Vis. 2005, 11, 425-430. 
106. Wang, L.; Xiao, R.; Andres-Mateos, E.; Vandenberghe, L.H. Single stranded adeno-associated virus achieves efficient gene transfer to anterior segment in the mouse eye. PLoS One 2017, 12, doi:10.1371/journal.pone.0182473

107. Lee, S.H.; Sim, K.S.; Kim, C.Y.; Park, T.K. Transduction Pattern of AAVs in the Trabecular Meshwork and Anterior-Segment Structures in a Rat Model of Ocular Hypertension. Mol. Ther. - Methods Clin. Dev. 2019, 14, 197-205, doi:10.1016/j.omtm.2019.06.009.

108. Peng, Y.; Tang, L.; Zhou, Y. Subretinal Injection: A Review on the Novel Route of Therapeutic Delivery for Vitreoretinal Diseases. Ophthalmic Res. 2017, 58, 217-226.

109. Ochakovski, G.A.; Bartz-Schmidt, K.U.; Fischer, M.D. Retinal Gene Therapy: Surgical Vector Delivery in the Translation to Clinical Trials. Front. Neurosci. 2017, 11, 1-7, doi:10.3389/fnins.2017.00174.

110. Omari, A.; Mahmoud, T.H. Vitrectomy; StatPearls Publishing, 2020;

111. Petit, L.; Ma, S.; Cheng, S.Y.; Gao, G.; Punzo, C. Rod Outer Segment Development Influences AAV-Mediated Photoreceptor Transduction after Subretinal Injection. Hum. Gene Ther. 2017, 28, 464-481, doi:10.1089/hum.2017.020.

112. Petit, L.; Khanna, H.; Punzo, C. Advances in gene therapy for diseases of the eye. Hum. Gene Ther. 2016, 27, 563579 .

113. Harvey, A.R.; Kamphuis, W.; Eggers, R.; Symons, N.A.; Blits, B.; Niclou, S.; Boer, G.J.; Verhaagen, J. Intravitreal injection of adeno-associated viral vectors results in the transduction of different types of retinal neurons in neonatal and adult rats: A comparison with lentiviral vectors. Mol. Cell. Neurosci. 2002, 21, 141-157, doi:10.1006/mcne.2002.1168.

114. Hellström, M.; Ruitenberg, M.J.; Pollett, M.A.; Ehlert, E.M.E.; Twisk, J.; Verhaagen, J.; Harvey, A.R. Cellular tropism and transduction properties of seven adeno-associated viral vector serotypes in adult retina after intravitreal injection. Gene Ther. 2009, 16, 521-532, doi:10.1038/gt.2008.178.

115. Igarashi, T.; Miyake, K.; Asakawa, N.; Miyake, N.; Shimada, T.; Takahashi, H. Direct comparison of administration routes for aav8-mediated ocular gene therapy. Curr. Eye Res. 2013, 38, 569-577, doi:10.3109/02713683.2013.779720.

116. Auricchio, A.; Kobinger, G.; Anand, V.; Hildinger, M.; O’Connor, E.; Maguire, A.M.; Wilson, J.M.; Bennett, J. Exchange of surface proteins impacts on viral vector cellular specificity and transduction characteristics: the retina as a model. Hum. Mol. Genet. 2001, 10, 3075-3081, doi:10.1093/hmg/10.26.3075.

117. Mori, K.; Gehlbach, P.; Ando, A.; Wahlin, K.; Gunther, V.; McVey, D.; Wei, L.; Campochiaro, P.A. Intraocular adenoviral vector-mediated gene transfer in proliferative retinopathies. Investig. Ophthalmol. Vis. Sci. 2002, 43, 1610-1615.

118. Moore, N.A.; Bracha, P.; Hussain, R.M.; Morral, N.; Ciulla, T.A. Gene therapy for age-related macular degeneration. Expert Opin. Biol. Ther. 2017, 17, 1235-1244, doi:10.1080/14712598.2017.1356817.

119. Wallace, D.K.; Dean, T.W.; Hartnett, M.E.; Kong, L.; Smith, L.E.; Hubbard, G.B.; McGregor, M. Lou; Jordan, C.O.; Mantagos, I.S.; Bell, E.F.; et al. A Dosing Study of Bevacizumab for Retinopathy of Prematurity: Late Recurrences and Additional Treatments. Ophthalmology 2018, 125, 1961-1966, doi:10.1016/j.ophtha.2018.05.001.

120. Rakoczy, E.P.; Lai, C.-M.; Magno, A.L.; Wikstrom, M.E.; French, M.A.; Pierce, C.M.; Schwartz, S.D.; Blumenkranz, M.S.; Chalberg, T.W.; Degli-Esposti, M.A.; et al. Gene therapy with recombinant adeno-associated vectors for neovascular age-related macular degeneration: 1 year follow-up of a phase 1 randomised clinical trial. Lancet 2015, 386, 2395-2403, doi:10.1016/S0140-6736(15)00345-1.

121. Fitzpatrick, Z.; Leborgne, C.; Barbon, E.; Masat, E.; Ronzitti, G.; van Wittenberghe, L.; Vignaud, A.; Collaud, F.; Charles, S.; Simon Sola, M.; et al. Influence of Pre-existing Anti-capsid Neutralizing and Binding Antibodies on AAV Vector Transduction. Mol. Ther. - Methods Clin. Dev. 2018, 9, 119-129, doi:10.1016/j.omtm.2018.02.003. 
122. Benveniste, O.; Boutin, S.; Monteilhet, V.; Veron, P.; Leborgne, C.; Montus, M.F.; Masurier, C. Prevalence of Serum IgG and Neutralizing Factors Against Adeno-Associated Virus (AAV) Types 1,2,5,6,8, and 9 in the Healthy Population: Implications for Gene Therapy Using AAV Vectors. Hum. Gene Ther. 2010, 21, 704-712, doi:10.1089/hurn.2009.182.

123. Bennett, J.; Wellman, J.; Marshall, K.A.; McCague, S.; Ashtari, M.; DiStefano-Pappas, J.; Elci, O.U.; Chung, D.C.; Sun, J.; Wright, J.F.; et al. Safety and durability of effect of contralateral-eye administration of AAV2 gene therapy in patients with childhood-onset blindness caused by RPE65 mutations: a follow-on phase 1 trial. Lancet 2016, 388, 661-672, doi:10.1016/S0140-6736(16)30371-3.

124. Veleri, S.; Lazar, C.H.; Chang, B.; Sieving, P.A.; Banin, E.; Swaroop, A. Biology and therapy of inherited retinal degenerative disease: insights from mouse models. Dis. Model. Mech. 2015, 8, 109-129.

125. Yla-Herttuala, S., Alitalo, K. Gene transfer as a tool to induce therapeutic vascular growth. Nat. Med. 2003, 9, 694-701, doi:10.1055/s-2005-872984.

126. Spooner, K.; Hong, T.; Wijeyakumar, W.; Chang, A.A. Switching to aflibercept among patients with treatmentresistant neovascular age-related macular degeneration: A systematic review with meta-analysis. Clin. Ophthalmol. 2017, 11, 161-177.

127. Yang, S.; Zhao, J.; Sun, X. Resistance to anti-VEGF therapy in neovascular age-related macular degeneration: A comprehensive review. Drug Des. Devel. Ther. 2016, 10, 1857-1867.

128. Georgiadis, A.; Duran, Y.; Ribeiro, J.; Abelleira-Hervas, L.; Robbie, S.J.; Sünkel-Laing, B.; Fourali, S.; GonzalezCordero, A.; Cristante, E.; Michaelides, M.; et al. Development of an optimized AAV2/5 gene therapy vector for Leber congenital amaurosis owing to defects in RPE65. Gene Ther. 2016, 23, 857-862, doi:10.1038/gt.2016.66. 